\title{
Arcabouço estrutural da Bacia do São Francisco nos arredores da Serra da Água Fria (MG), a partir da integração de dados de superfície e subsuperfície
}

\author{
Cízia Mara Hercos ${ }^{1}$, Marcelo Augusto Martins-Neto ${ }^{2}$ \& André Danderfer Filho ${ }^{3}$
}

\begin{abstract}
Resumo A porção leste da Bacia do São Francisco, nos arredores da serra da Água Fria, conta com uma seção sísmica (240-RL-300) de direção NW-SE. Ao longo dessa seção foi possível reconhecer os estilos estruturais dominantes no segmento estudado e constatar que o mesmo pertence a um compartimento tectônico, denominado Saliência de Pirapora, onde o embasamento foi envolvido na deformação das rochas da cobertura (tectônica thickskinned). A partir da integração dos dados sísmicos e de campo, foi possível dividir esse segmento em 3 domínios estruturais: Oriental, Central e Ocidental, que são caracterizados, no nível estrutural mais raso, pela presença de megadobras, uma extensa monoclinal (Monoclinal do Boqueirão) e estratos suborizontais, respectivamente. A deformação é maior no domínio Oriental e diminui em direção ao Ocidental. No domínio Oriental foi constatado um soerguimento do relevo estrutural de cerca de $2500 \mathrm{~m}$; em profundidade, nos arredores da serra da Água Fria, foi interpretado um hemigráben invertido (inversão fraca) balizado a oeste por um alto de embasamento (Alto do Boqueirão), recoberto em contato discordante por uma unidade que exibe maior encurtamento relacionado ao desenvolvimento das megadobras. $\mathrm{O}$ alto do Boqueirão atuou como um anteparo rígido (butress), causando o encurtamento da sequência sin-rifte ao bloquear o transporte tectônico dirigido para oeste. A monoclinal do Boqueirão foi gerada em resposta ao soerguimento desse alto durante a inversão da bacia. $\mathrm{O}$ encurtamento total da área foi acomodado por dois mecanismos: inversão de falhas normais em resposta ao soerguimento regional do embasamento, e dobramentos na cobertura amplificados por esforços horizontais.
\end{abstract}

Palavras-chaves: Cráton São Francisco, Tectônica, Geologia Estrutural, Bambuí, Formação Jequitaí.

\begin{abstract}
Structural framework of the São Francisco Basin around Agua Fria Range (Minas Gerais, Brazil), from the integration of surface and subsurface data. The Água Fria Range, located in the eastern portion of the São Francisco Basin, central Brazil, has an essential unique seismic profile (240-RL300). This section allows the interpretation of the three main structural styles recognizable in this area, which belongs to a tectonic compartment named "Pirapora Salient", which is characterized by basement-involved deformation syngenetic to a tectonic inversion of an "intracratonic" basin. Integration of both seismic and field data made possible to establish three structural domains: Eastern, Central and Western. They are defined in the shallower tectonic level respectively as: a fault-related folds predominance; an extensive monoclinal; undulated subhorizontal strata. The deformation rate decreases westward. The eastern domain shows a dramatic structural relief of about $2500 \mathrm{~m}$ resulting from a strong uplift of this portion related to a regional datum. Deeper structural investigation around Água Fria Range shows an inverted half-graben (Mild Inversion), which is limited by a basement high in its western border (Boqueirão High). While the easternmost normal fault system of Boqueirão High experimented weak structural inverson, the associated covering strata underwent significative shortening as a result of folding related to horizontal displacement. The Boqueirão High formed a rigid buttress that controlled the internal folding/shortening of the synrift sequence. The generation of the Boqueirão Monoclinal was governed by the uplift of the Boqueirão High.The total shortening throughout the area is a result of two mechanisms: the inversion of originally normal faults asssociated to uplift of the basement blocks, together with the folding of covering strata enlarged by horizontal forces.
\end{abstract}

Keywords: São Francisco craton, tectonics, structural geology, Bambuí, Jequitaí Formation.

INTRODUÇÃO A Bacia do São Francisco tem sido objeto de estudo de diferentes gerações de geólogos, contudo a sua própria definição ainda é controvertida. Neste trabalho será adotada a definição de que essa bacia seria composta por bacias sucessoras (Alckmin \& Martins-Neto 2001), que se desenvolveram no tempo a partir do Mesoproterozóico Superior. O preenchimento sedimentar de tais bacias está representado pelos grupos Canastra e Paranoá (Mesoproterozóico Superior/ Neoproterozóico) e Supergrupo São Francisco (Neoproterozóico), recobertas em parte por coberturas fanerozóicas.

O conhecimento acerca da formação, preenchimento e deformação da cobertura meso e neoprotero-

1 - Petróleo Brasileiro S/A, Vitória (ES), Brasil. E-mail: cizia@petrobras.com.br

2 - PGT-Petroleum Geoscience Technology Ltda, 35400-000, Ouro Preto (MG), Brasil. E-mail: marcelo.martins@pgt.com.br,

3 - Caixa Postal 239, 35400-000, Ouro Preto (MG), Brasil. E-mail: andré@degeo.ufop.br 
zóica situada sobre o cráton São Francisco teve grande desenvolvimento nas duas últimas décadas, impulsionado pelo estudo de subsuperfície, a partir de sondagens efetuadas pela CPRM (Brandalise 1980) e Petrobras (1991), levantamentos aeromagnetométricos e gravimétricos (Bosun 1973, Lesquer et al. 1981, Petrobras 1991) e sísmica de reflexão (Petrobras 1992).

O presente trabalho será dedicado à caracterização dos estilos e domínios estruturais da área, bem como à reconstrução do arcabouço tectônico $2 \mathrm{D}$ através do segmento estudado, retratando os efeitos decorrentes das fases de formação e de inversão na borda leste da bacia, utilizando dados de poços e sísmica multicanal 2D de forma integrada com dados de campo. Para tanto foi escolhida uma área situada na porção centronorte do Estado de Minas Gerais, a nordeste da cidade de Pirapora, que engloba as serras da Água Fria e da Onça bem como a planície do Rio Jequitaí, situada entre ambas as serras (Fig. 1).

A área de interesse é cortada pela seção sísmica 240-RL-300 que se estende desde o flanco oeste da serra da Água Fria até $95 \mathrm{~km}$ a noroeste, quando então se inicia a seção $240-R L-60$, sobre a qual está localizado o poço 1-RF-1-MG. Através da análise conjunta dessas duas seções sísmicas constatou-se que várias unidades estratigráficas profundas, não atravessadas pelo poço 1-RF-1-MG, poderiam aflorar na serra da Água Fria.

Apesar da seção sísmica não ter alcançado a serra do Cabral, foi possível visualizar estruturas que provavelmente têm continuação para leste, em direção á referida serra. Tais estruturas forneceram subsídios para a construção de um novo modelo para explicar a exumação de rochas pertencentes à seqüência basal da bacia (Sg. Espinhaço) nas anticlinais das serras da Água Fria e do Cabral.

ARCABOUÇO GEOLÓGICO O segmento investigado compreende os compartimentos indeformado (C - central) e deformado de antepaís (E - leste) da porção oriental do cráton São Francisco (Fig. 2), tal como definidos por Alckmin et al. (1993); a leste o cráton é margeado pela faixa Araçuaí. O cráton São Francisco foi definido por Almeida (1977) como uma porção da plataforma Sul-Americana, consolidada como segmento litosférico no arqueano e moldada pela orogênese Brasiliana (650-450Ma).

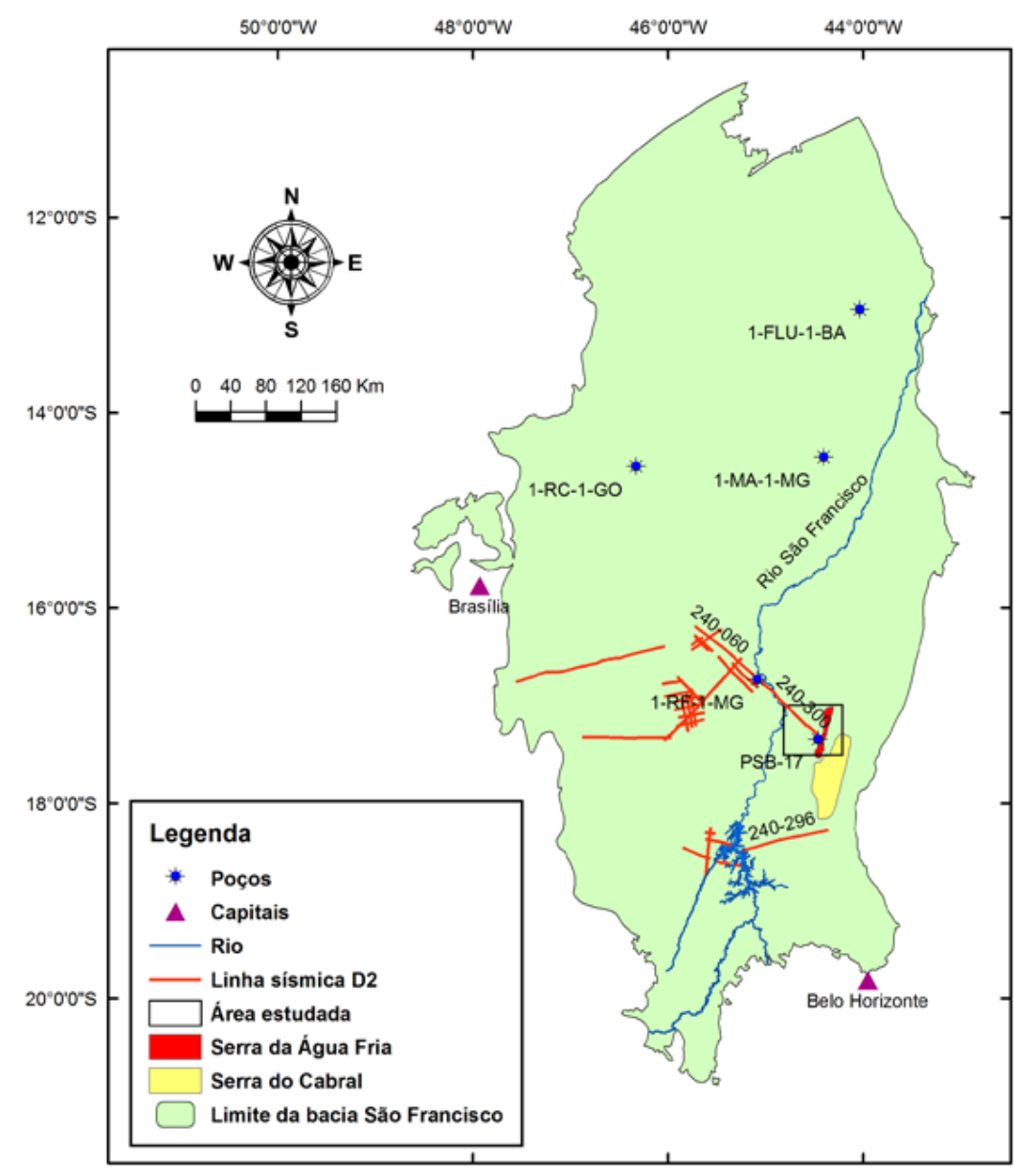

Figura 1- Mapa do contorno da Bacia do São Francisco contendo a localização da área estudada, bem como dos dados sísmicos e de poços utilizados na elaboração do presente estudo (Modificado de Fugita \& Clark 2001). 
A faixa Araçuaí (Almeida 1977) é um cinturão de dobramentos e cavalgamentos neoproterozóico com vergência para oeste, no sentido do cráton São Francisco, originado durante a orogenia brasiliana-panafricana. Estende-se por cerca de $1000 \mathrm{~km}$ na direção norte-sul, desde Ouro Preto (MG) até o sul da Bahia, e chega a alcançar $400 \mathrm{~km}$ de largura. Em geral o limite entre a faixa Araçuaí e o cráton São Francisco é marcado por uma falha inversa que envolve o embasamento na deformação da cobertura (Alckmin et al. 1993). Por sua vez, no compartimento estrutural $\mathrm{E}$ as rochas da cobertura cratônica apresentam deformação epidérmica (thin-skinned), com mecanismo motriz focado no interior dessa faixa.

No compartimento leste afloram rochas dos supergrupos Espinhaço e São Francisco sobrepostas em alguns locais por sucessões sedimentares mesocenozóicas, relacionadas por Sgarbi et al. (2001) com o Grupo Areado (Cretáceo) e a Formação Chapadão (Terciário). Os metassedimentos do Supergrupo Espinhaço (Inda et al. 1984) afloram nos núcleos dos anticlinórios das serras da Água Fria e do Cabral (Carvalho \& Epstein 1967, Paiva \& Ponçano 1972, Viveiros e Walde 1976, Walde 1978, Uhlein 1991, Dupont 1995, Souza Filho 1995 e Espinoza 1996). Na Serra do Cabral são reconhecidas as formações Galho do Miguel, Santa Rita e Córrego dos Borges (Ulhein 1991, Dupont 1995, Espinoza 1996). Na Serra da Água Fria, expostos ao longo do canyon do rio Jequitá, sucede uma seqüência de arenitos e pelitos cortada por intrusivas básicas e relacionada com o Supergrupo Espinhaço (Gomes 1949, Paiva \& Ponçano 1972).

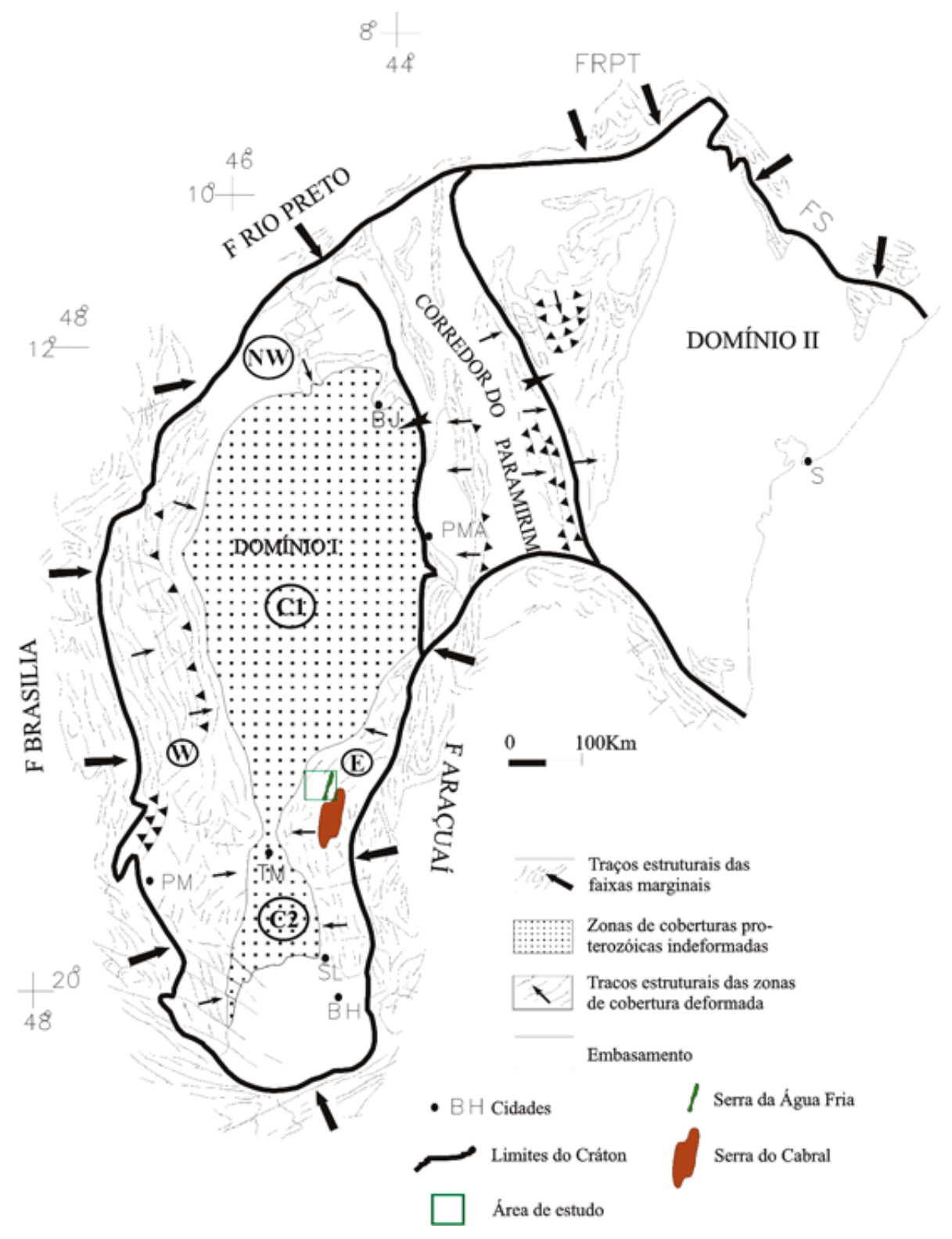

Figura 2 - Domínios estruturais do Cráton do São Francisco e traços gerais da deformação das coberturas proterozóicas (Modificado de Alkmim et al. 1993). 
O Supergrupo São Francisco é representado na região por depósitos areno-diamctíticos da Formação Jequitaí (glaciogênico; Walde 1978, Isotta et al. 1969, Paiva \& Ponçano 1972, Gravenor e Monteiro 1983, Oliveira 1989, Hercos \& Martins-Neto 1997) e rochas pelito-carbonáticas do Grupo Bambuí (marinho plataformal). O contato com o Supergrupo Espinhaço é marcado por discordância regional, erosiva e angular (Dupont 1995, Souza Filho 1995, Espinoza 1996). As rochas da Formação Jequitaí ocorrem sotopostas às do Grupo Bambuí, tendo sido na literatura correlacionados aos depósitos glácio-marinhos do Grupo Macaúbas no domínio da Faixa Araçuaí (Moraes \& Guimarães 1930, Viveiros \& Walde 1976, Oliveira 1989, Bacellar 1989, Ulhein 1991, Martins-Neto \& Hercos 2002, Hercos 2008).

Já o Grupo Bambuí compreende uma sucessão diferente daquela reconhecida nas regiões central e sudeste da bacia por Branco \& Costa (1961). Walde (1978), Oliveira (1989), Souza Filho (1995) e Dupont (1996) ressaltam a ausência dos carbonatos basais da Formação Sete Lagoas nessa sucessão. Souza Filho (1995) sugere para a área um empilhamento que se inicia com rochas do Subgrupo Paraopeba e completa-se com os litotipos da Formação Três Marias.

Os arenitos observados na base da sucessão sedimentar da área em questão foram correlacionados ás formações superiores do Grupo Conselheiro Mata. Sobre eles assentam-se discordantemente depósitos areno-diamictíticos da Fm Jequitaí que, neste trabalho, são considerados cronocorrelatos à Fm Macaúbas. Acima destes, em ligeira discordância angular, repousam depósitos pelíticos e de ritmitos silto-arenosos e margosos. Esses depósitos se encontram sobrepostos por uma alternância de sequências pelíticas e pelito-carbonáticas. Sobrepõem-se, em contato discordante, conglomerados e arenitos de idade cretácica que são atribuídos ao Grupo Areado - Fm Abaeté (Costa et al 1998).

Os aspectos relacionados com geologia estrutural da área foram investigados com maior detalhe por Souza Filho (1995), o qual divide a região da Serra do Cabral em macro-domínios de diferentes estilos tectônicos (macro-domínios Espinhaço e São Francisco) controlados pelas suas características reológicas. Além disso, subdivide o macro-domínio São Francisco em 3 domínios com base no decréscimo de intensidade tectônica (Fig. 3). Segundo o autor a estruturação da região é constituída por amplas culminações antiformais e depressões sinformais desenvolvidas nos dois supergrupos, com formas abertas e cônicas, exibindo vergência para oeste. As charneiras das dobras apresentam duplo caimento em torno das direções N15E e S15W, com desvios para NNW e SSE.

Os dados geofísicos apontam que o embasamento da bacia São Francisco encontra-se estruturado em altos e baixos. Na região cratônica a sul do paralelo $14^{\circ} \mathrm{S}$, foram reconhecidas anomalias gravimétricas negativas de direção N35E, contíguas a altos gravimétricos alongados na direção NE-SW (Lesquer et al. 1981). A partir da modelagem da anomalia gravimétrica de

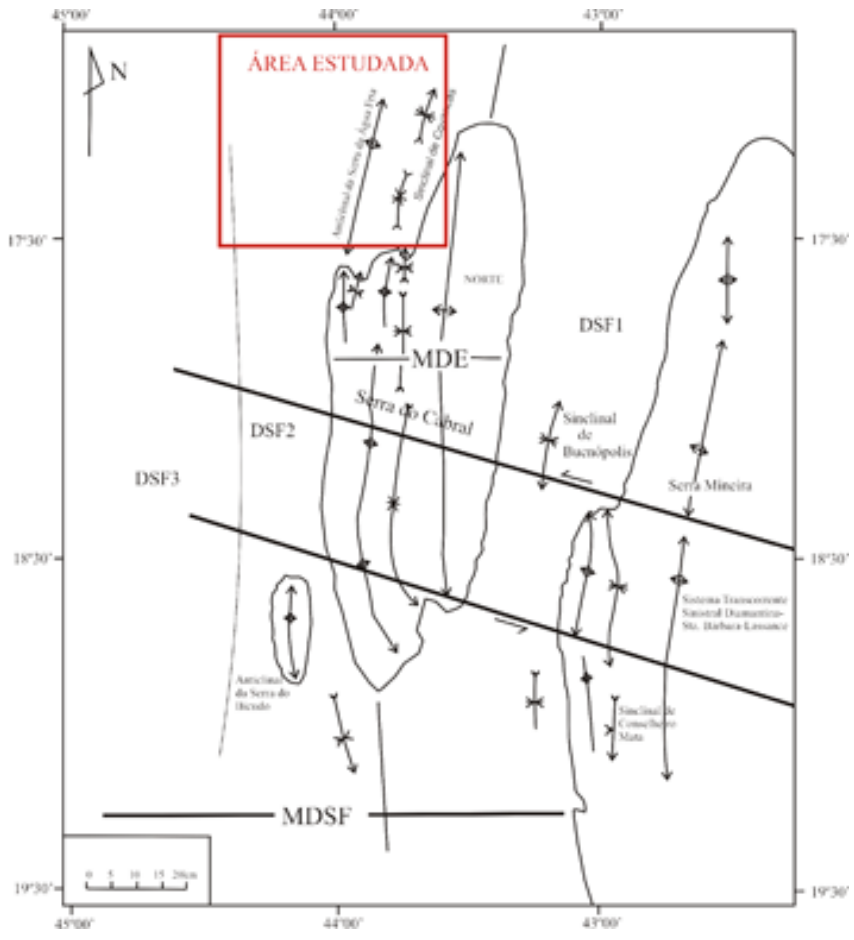

Figura 3 - Mapa de domínios estruturais da região da serra do Cabral e adjacências (Modificado de Souza Filho 1995).

Pirapora, Ussami (1981) propõe a existência de um corpo retangular de baixa susceptibilidade magnética em grande profundidade, alongado na direção NW-SE. Teixeira et al. (1993) sugerem a existência de um depocentro sobre essa anomalia, controlado por uma falha normal de grande rejeito de direção E-W. Marinho (1993), a partir de dados gravimétricos, estima para o embasamento profundidades variando de $2 \mathrm{~km}$ (a NW de São Romão) a $5 \mathrm{~km}$ (a SW de Santa Fé). Segundo o autor, o embasamento estaria a grandes profundidades na região de Pirapora.

Os dados sísmicos indicam a existência de blocos escalonados limitados por falhas (grábens e horsts) na seção basal da bacia São Francisco (Teixeira et al. 1993). Os dados dos poços também corroboram essa interpretação. Segundo Braun et al. (1993), na porção oriental da bacia, a maioria das falhas, originalmente normais, foi reativada por movimentos reversos para noroeste e norte que não atingem o Bambuí. Braun et al. (1993) e Teixeira et al. (1993), ao analisarem as seções sísmicas levantadas pela Petrobras (1992) entre a região do Remanso do Fogo e o rio Urucuia, propõem a existência de duas seqüências deposicionais basais (Espinhaço e Macaúbas) instaladas em grábens e horsts, separadas de uma seqüência superior (Bambuí) por um horizonte sísmico bem marcado, representativo de uma discordância regional. Martins-Neto (2005) e RomeiroSilva \& Zalán (2005) também reconhecem o caráter distinto dessas duas sequências, porém estabelecem diferentes correlações com a litoestratigrafia formal, as quais não serão abordadas neste trabalho. 
MÉTODO O método utilizado para reconstruir o arcabouço estrutural da área consistiu na integração de dados de superfície e de subsuperfície, seguido do emprego de algumas técnicas de modelagem estrutural. Primeiramente foi elaborada a base cartográfica para coligir informações geológicas existentes e para representar os dados estruturais de campo; foram utilizadas as folhas Jequitaí e Pirapora 1:100.000, do IBGE e os dados do sensor TM 5 do Landsat (bandas 3, 4 e 5).

A área é atravessada pela seção sísmica 240RL-300 que se estende até o flanco oeste da serra da Água Fria (Fig. 4). Essa seção foi locada sobre a base cartográfica, permitindo definir a faixa a ser mapeada. Os trabalhos de campo foram concentrados nas serras da Água Fria, da Onça e das Porteiras onde ocorrem as melhores exposições. O restante da área é constituído principalmente por cobertura aluvionar pertencente à bacia hidrográfica do Rio Jequitaí que é afluente do Rio São Francisco.

Além da seção 240-RL-300 foi utilizada a seção sísmica 240-RL-60 bem como os dados dos poços 1-RF-1-MG e 1-PSB-17 perfurados pela Petrobras e CPRM, respectivamente. Os poços 1-RF-1-MG e PSB17 perfuraram 1842 e 264 m de seção sedimentar, respectivamente.

A seguir foram mapeados os principais refletores das duas seções sísmicas, em tempo, gerando um line drawing. A seção RL 240-300 foi convertida em profundidade através de uma conversão linear pelo método do raio vertical, utilizando o programa de processamento sísmico PROMAX (Landmark). Através da sísmica foi possível estender a correlação do local do poço 1-RF-1 até a serra da água Fria ao longo das seções RL-060 e RL-300.

Em função do estilo estrutural observado, foi escolhido o método do Kink para extrapolar e interpolar contatos na seção a partir da sua interseção em superfície. A seção geológica final reconstitui o arcabouço tectônico da área, permitindo tecer considerações sobre a evolução estrutural do segmento cratônico em questão. A reconstrução da geometria das dobras é balizada pelas falhas interpretadas na seção sísmica em profundidade.

Por fim, a caracterização tectono-estratigráfica da área baseou-se, principalmente, em duas seções geológicas de direção NW-SE que foram correlacionadas: uma delas (seção $\mathrm{AB}$ ) é coincidente com a seção sísmica RL-300 até o alto da serra da Água Fria, a partir desse ponto se prolonga até a serra do Cabral, tendo sido complementada nesse último trecho com dados de campo; a outra foi construída a partir de dados de campo coletados ao longo da serra da Onça (seção CD).

\section{INTEGRAÇÃO DE DADOS SÍSMICOS COM GEOLOGIA DE SUPERFÍCIE}

Arcabouço Sismo-estratigráfico Na seção 240-RL300 foram observadas no mínimo 2 megasseqüências, no sentido de Hubbard (1985), com caráter sísmico bem distinto: uma basal de caráter extensional (Megasseqüência I), constituindo o preenchimento de grábens

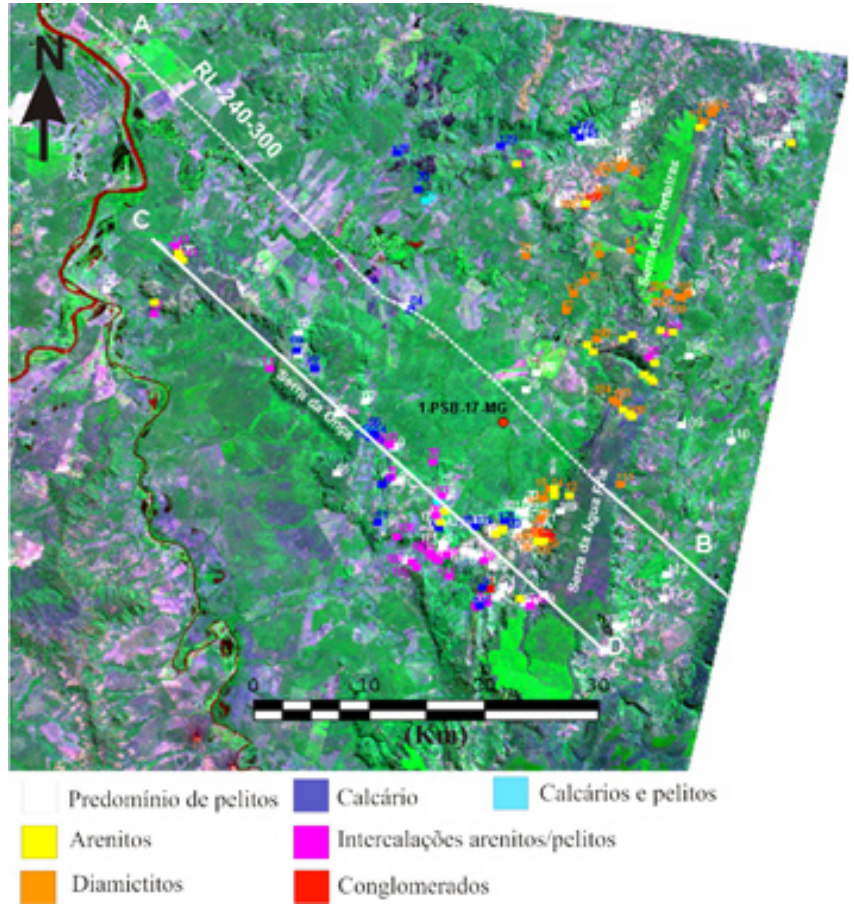

Figura 4 - Imagem de satélite Landsat TM com a localização das seções geológicas $A B$ e CD, da seção sísmica RL-300 e dos afloramentos investigados.

e hemigrábens limitados por horsts, e uma superior (Megasseqüência S), com estratos paralelos a subparalelos que recobrem as estruturas tafrogênicas (Figs. 5 e 6). O limite entre ambas ocorre ao longo de uma discordância de caráter regional. Essa discordância foi observada também na seção 240-RL-60, a oeste, e em outras seções sísmicas da mesma bacia (Teixeira et al. 1993, Braun et al. 1993, Romeiro-Silva \& Zálan 2005, Martins-Neto 2005).

A correlação dos dados do poço 1-RF-1-MG com os padrões sísmicos de reflexão permitiu individualizar nas seções RL-060 e RL-300 três unidades sismo-estratigráficas (Fig. 6), apresentadas a seguir da base para o topo. A unidade As reúne os depósitos que ocupam as depressões (grábens) observadas na Megasseqüência I. O topo da unidade As aflora nos flancos das anticlinais das serras da Água Fria e das Porteiras e ao longo do cânion do rio Jequitaí. Na serra da Água Fria afloram seqüências predominantemente areníticas com estruturas sedimentares indicativas de ambiente marinho plataformal raso e profundo, correlacionadas na literatura às formações superiores do Grupo Conselheiro Mata. Nos flancos oeste e leste da serra ocorrem estrias glaciais em arenitos do topo desta seqüência; no flanco ocidental as estrias apontam direção de transporte de leste para oeste.

Sobre os arenitos, assentam-se em discordância depósitos areno-diamictíticos e conglomeráticos, glaciogênicos, denominados na literatura de Formação Jequitaí, aqui correlacionados ao Grupo Macaúbas e posicionados na fase rifte da bacia homônima. A integração 


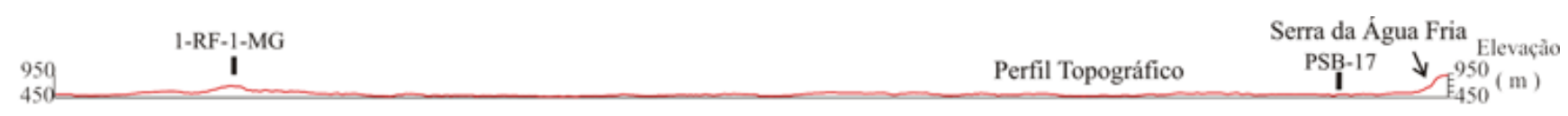

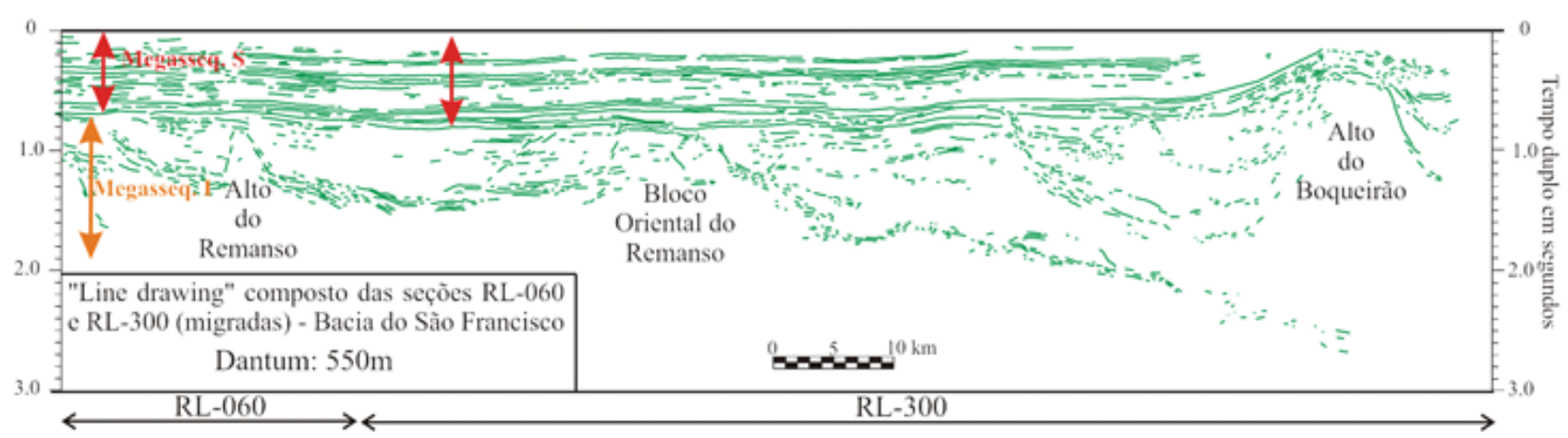

Figura 5 - Line drawings das seções RL-060 e 300.

dos dados da seção RL-300 com os de campo indica que os depósitos dessa unidade estão aprisionados em um hemigráben que se desenvolveu a oeste da serra da Água Fria. O limite superior da unidade As com a unidade Bs ocorre através de uma discordância regional bem caracterizada na sísmica, porém representada por uma discordância angular sutil no campo.

$\mathrm{Na}$ seção sísmica, a unidade Bs foi subdividida em duas subunidades: Bs1 (inferior) e Bs2 (superior). A subunidade Bs2 apresenta refletores contínuos, paralelos a subparalelos, que na área do poço 1-RF-1 correspondem a uma seqüência pelito-carbonática de $140 \mathrm{~m}$ de espessura, sobrepondo um nível de conglomerado com $7 \mathrm{~m}$ de espessura, sotoposto por um depósito composto por quartzo e fragmentos de rochas sedimentares e uma fração mais fina argilo-arenosa (descrição de amostra de calha). Já na porção basal (subunidade Bs1) são comuns superfícies erosivas limitando pacotes sedimentares que apresentam variação lateral de espessura; distinguem-se feições canalizadas onde foram observadas terminações laterais em onlap. As superfícies erosivas truncam refletores subjacentes. No interior das feições canalizadas observa-se sismofácies transparente, sem reflexões internas, que podem corresponder a depósitos grossos (arenitos ou conglomerados) ou pelíticos. O poço 1-RF-1 não amostrou a subunidade Bs2. A unidade Bs representaria o registro da fase flexural da Bacia Macaúbas.

A unidade Cs é caracterizada por refletores sísmicos de alta amplitude, contínuos, que se alternam a intervalos com ausência de reflexões. Ela é constituída por intercalações de pelitos e carbonatos que foram organizados em 5 subunidades, enumeradas em ordem crescente da base para o topo, de acordo com o litotipo predominante, se pelito (unidades Cs1, Cs3 e Cs5) ou carbonato (unidades Cs2 e Cs4). Essas sucessões representam ciclos de shallowing upward, os quais foram relacionados ao preenchimento da bacia Bambuí.

Arcabouço Tectônico e análise estrutural A caracterização dos estilos e domínios estruturais da área e a reconstrução do arcabouço tectônico $2 \mathrm{D}$ através do segmento estudado retratam os efeitos decorrentes das fases de formação e inversão da bacia São Francisco. Durante a análise e integração dos dados se observou uma variação de estilos de acordo com o nível estrutural, se superficial, seção rasa ou profunda.

Na seção sísmica RL-300 nota-se uma conspícua diferença nos padrões de arranjo dos horizontes sísmicos entre a porção superior e inferior desta seção. A porção superior (zona SP) é caracterizada por refletores sísmicos bem marcados, aproximadamente paralelos, contínuos, que se alternam a intervalos sem reflexão. Estes refletores são adotados como os horizontes de referência para a interpretação da geometria estrutural, principalmente dobras, falhas e dobras associadas a falhas (fault-related folds; Fig. 7).

A porção inferior (zona IF) da seção é caracterizada por elevações e depressões que podem ser interpretadas como estruturas em horsts e grábens, respectivamente. Os limites entre esses blocos são conformados possivelmente por falhas de médio a alto ângulo que passam para baixo ângulo em profundidade. Os horsts são interpretados como altos do embasamento cristalino contendo alguma cobertura sedimentar no seu topo. No geral, a porção superior dos grábens se encontra preenchida por seqüências que não apresentam reflexões internas, e por isto foram correlacionadas a possíveis depósitos psamíticos por Teixeira et al. (1993).

A partir da integração da interpretação sísmica com os dados de campo, foi possível dividir o segmento estudado em 3 domínios estruturais: Oriental, Central e Ocidental, conforme dispostos na figura 8. A magnitude da deformação diminui consideravelmente de leste para oeste. A deformação ocorreu predominantemente em regime frágil nos 3 domínios. No entanto no Domínio Oriental ocorrem, em alguns locais, feições mais típicas de uma deformação frágil-dúctil observáveis, sobretudo, nos pelitos. O metamorfismo na área é incipiente o que permitiu a preservação das estruturas sedimentares primárias. $\mathrm{O}$ acamamento $\left(\mathrm{S}_{0}\right)$ pôde ser tomado ao longo da superfície deposicional dos estratos. 
NW

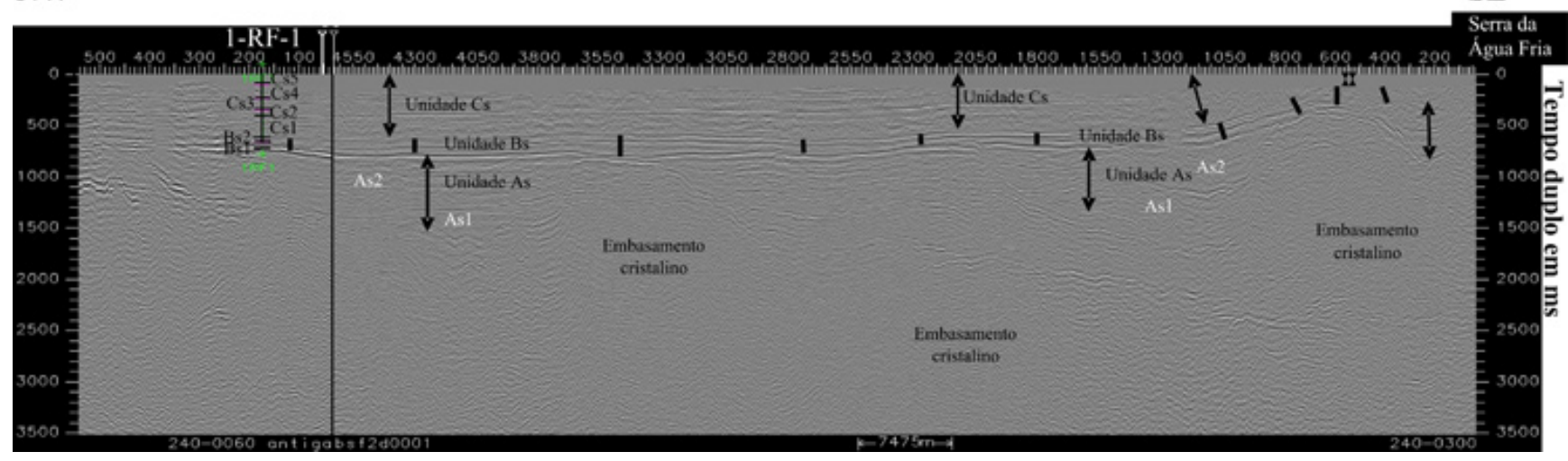

(A)

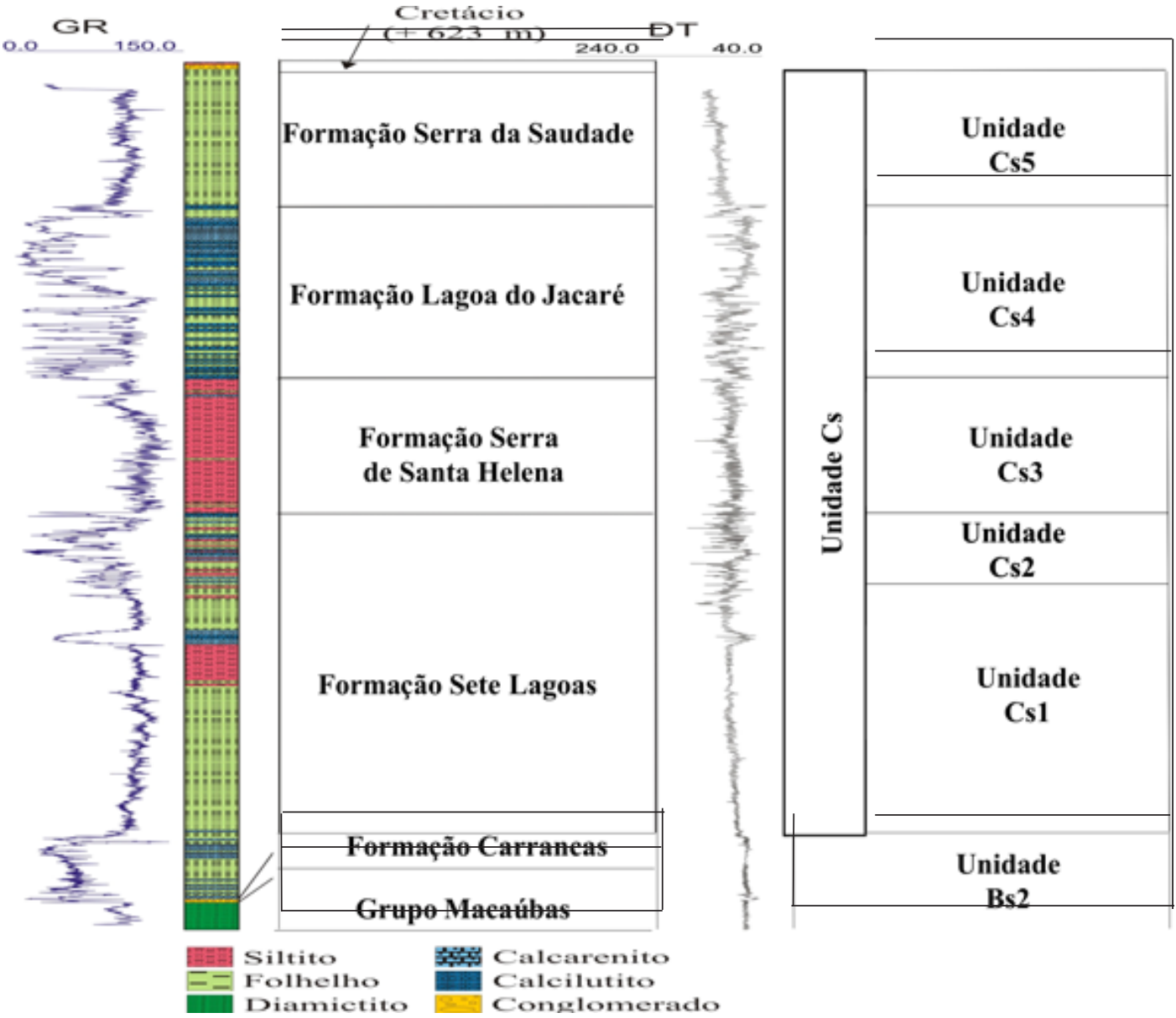

Figura 6 - Mostra a correlação entre o dado real, de poço, e o dado indireto, da sísmica. (A) unidades sismoestratigráficas reconhecidas nas seções sísmicas $R L-060$ e 300 e (B) correlação entre as unidades sismo-estratigráficas As, Bs e Cs e as unidades litoestratigráficas formais reconhecidas na área do poço 1-RF-1 por Fugita \& Clark (2001).

\section{DOMÍNIO ORIENTAL}

Em subsuperficie A oeste da serra da Água Fria se observa uma feição em "arpão" sobre uma depressão assimétrica que é balizada a oeste por uma falha com indicação de movimento reverso, limitando um bloco de embasamento cristalino, denominado de Alto do Boqueirão (zona IF). Debaixo dessa feição ocorre ainda uma falha normal invertida subsidiária à falha principal semelhante a uma falha de "atalho" (shortcut fault); as falhas exibem inclinações distintas, com a mais externa apresentando menor ângulo de mergulho aparente do que a interna. Esta estruturação foi associada a um hemigráben com inversão relativamente fraca, recoberto em contato discordante por uma unidade exibindo maior encurtamento das camadas (zona SP). A falha normal que limita essa estrutura foi reativada como in- 


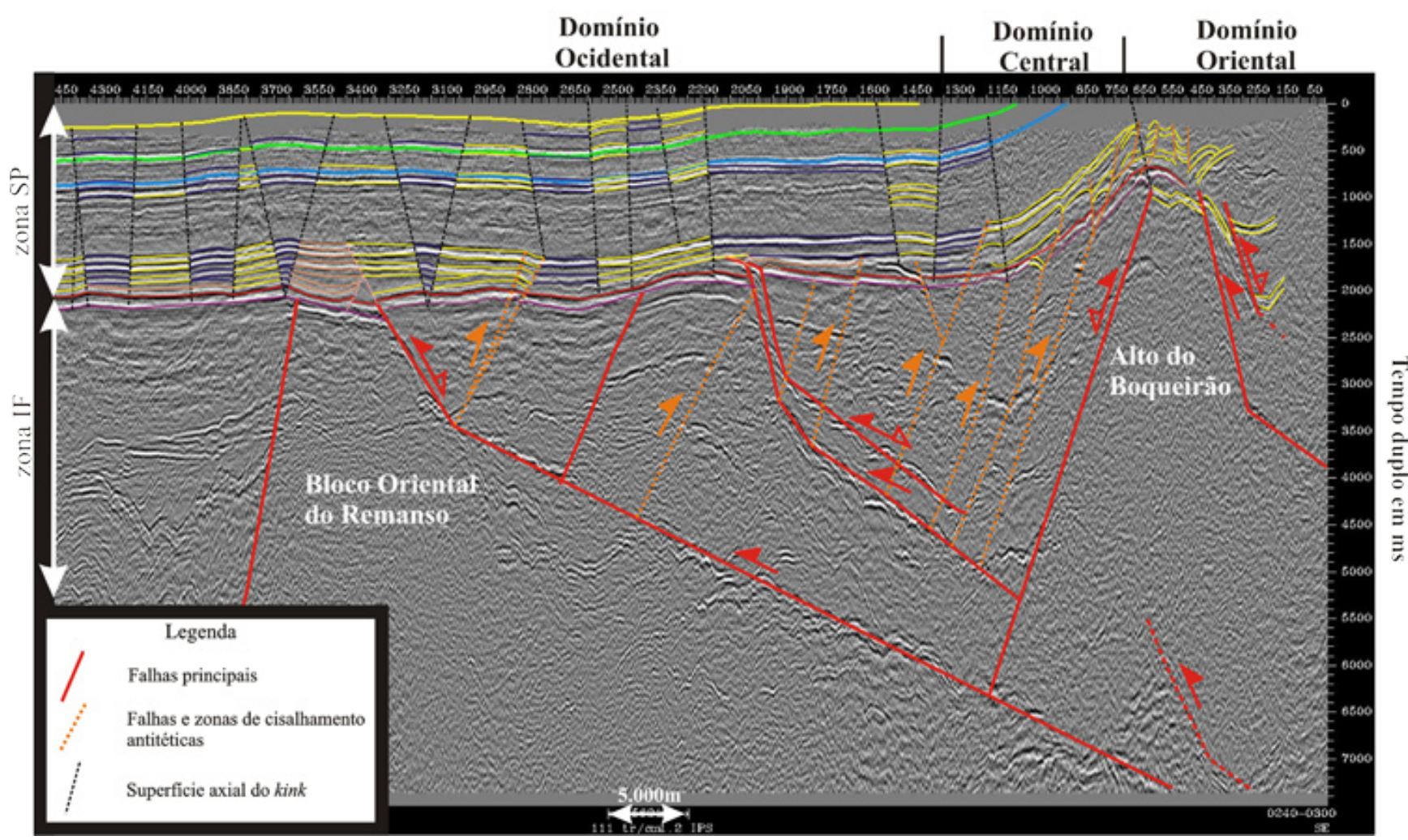

Figura 7 - Seção sísmica em tempo com interpretação dos traços estruturais.

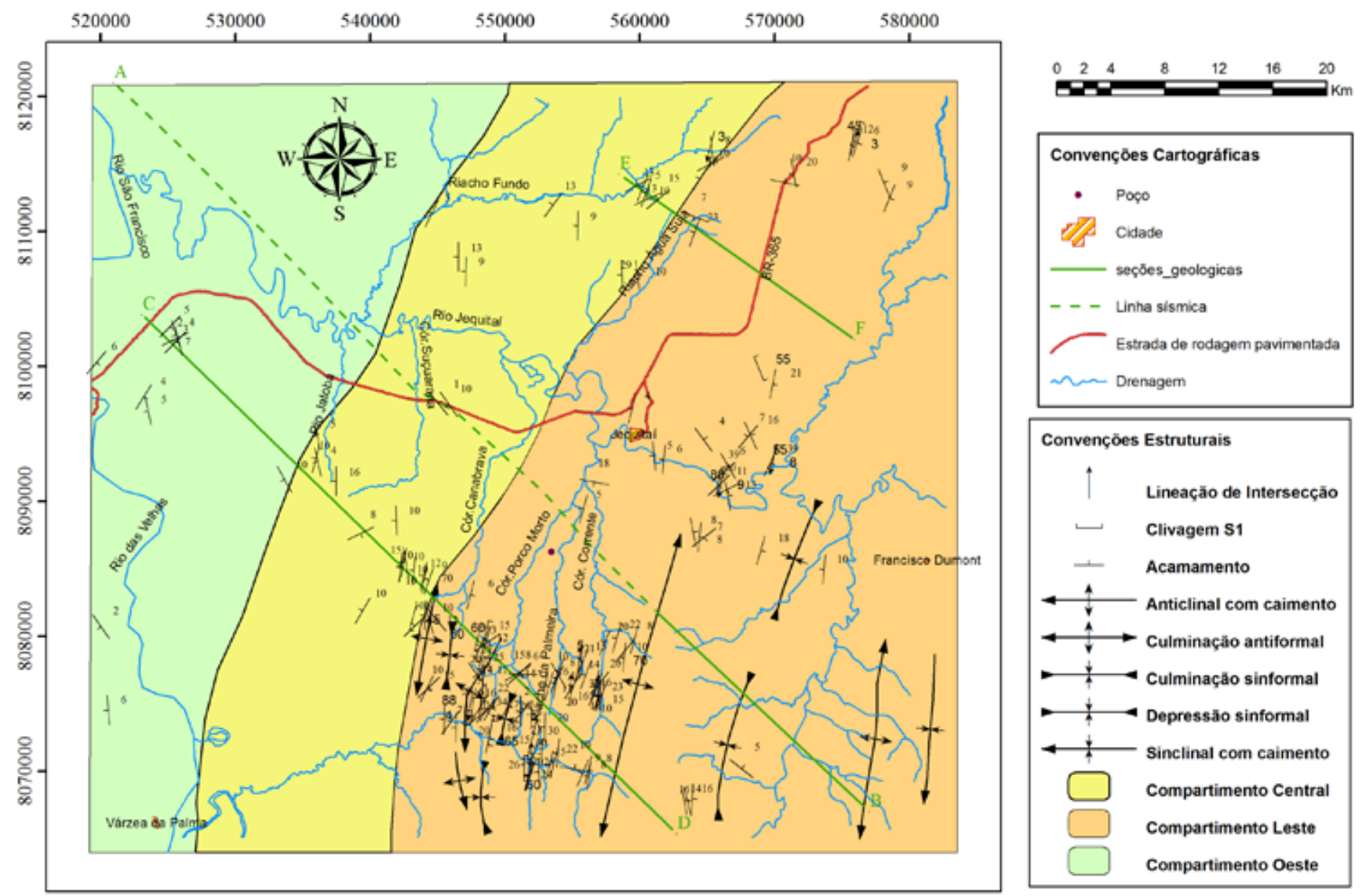

Figura 8 - Mapa de domínios estruturais. 
versa ao passo que a deformação da cobertura foi acomodada por dobras associadas a falhas (fault-related folds) que descolam no contato entre as zonas SP e IF (Figs. 9 e 10).

O Alto do Boqueirão atuou como um anteparo rígido (butress), bloqueando o transporte tectônico dirigido para oeste e causando o encurtamento da sequência sin-rifte (zona IF). Os estratos da unidade As2 revelam um encurtamento maior do que os estratos sobrejacentes (unidade Bs) e sotopostos (unidade As1) o que sugere a existência de um descolamento no contato entre elas. A geometria estrutural da unidade As2 lembra uma cunha estrutural (structural wedge), com descolamentos inferior e superior mostrando cinemáticas contrárias; no caso, a base com movimento para oeste, o topo, para leste.

Sobre o Alto do Boqueirão ocorrem horizontes ondulados seccionados por falhas. Foram reconhecidas dobras associadas a falhas do tipo fault-propagation folds, com vergência para leste, contrária à vergência tectônica da área oriental adjacente.

A unidade da cobertura, posicionada no segmento ocidental do hemigráben, é caracterizada por duas grandes dobras ligeiramente assimétricas, exibindo vergência para oeste. Estas dobras conformam uma sinclinal, adjacente a anticlinal da serra da Água Fria, e uma anticlinal que lhe sucede a oeste. É provável que a porção flexural do hemigráben se estenda sob a serra da Água Fria. Durante a inversão, esta porção experimentou um soerguimento de maior magnitude em comparação ao Alto do Boqueirão, provavelmente por ter sofrido um maior encurtamento. Modelos físicos que reproduzem a inversão de um hemigráben mostram a formação de uma grande antiforme sobre a porção flexural, seguida por uma sinforme e outra antiforme de menor tamanho, esta última posicionada sob a falha mestra do gráben (Fig. 11).

Nivel superficial O elemento estrutural predominante observado no nível superficial do domínio Oriental são

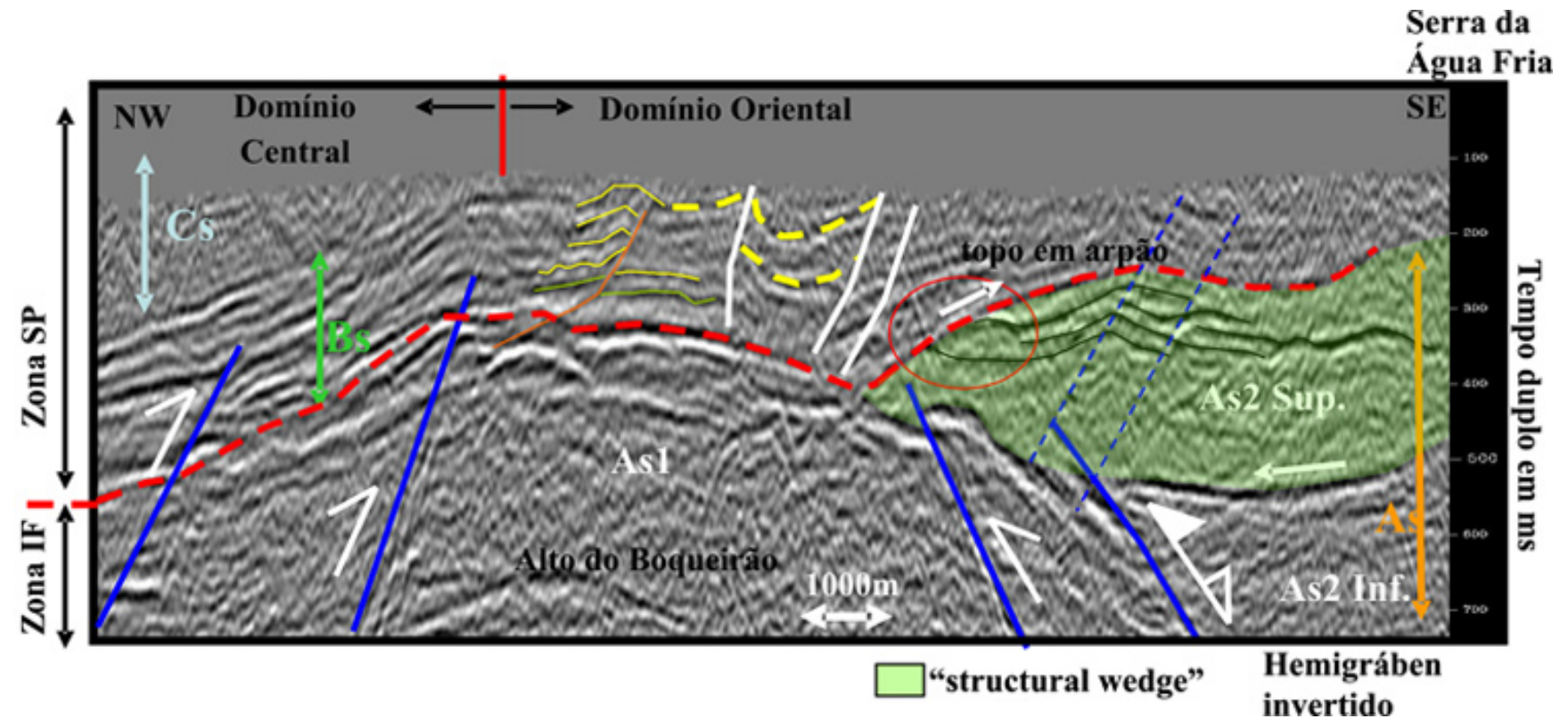

Figura 9 - Detalhe das feições estruturais do domínio Oriental.

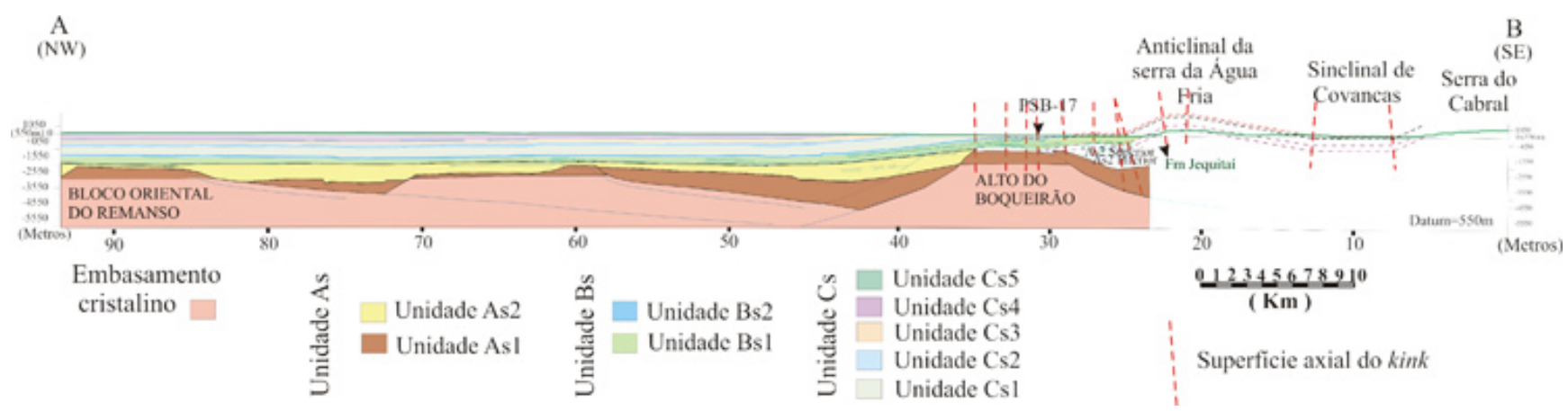

Figura 10 - Perfil AB coincidente com a seção RL-300 até o flanco oeste da serra da Água Fria. 
as dobras que, em geral, estão relacionadas à falhas em profundidade. As dobras são de diferentes magnitudes e estilos. Nesse domínio, os litotipos da unidade CS foram quase que totalmente erodidos, restando pouco mais de uma centena de metros sobre o Alto do Boqueirão.

Esse domínio é caracterizado pela presença de dobramentos de diferentes escalas, desde megadobras visíveis em imagens de satélite até dobras de menor ordem, em escala de afloramento, apresentando comprimentos de onda decamétricos a centimétricos (Fig. 12). Neste domínio a magnitude da deformação varia longitudinalmente, na direção norte-sul, de forma que as megadobras que ocorrem a oeste da serra da Água Fria parecem não ter continuidade para norte, além do rio Jequitaí. Nessa região, a deformação é acomodada por uma única culminação antiformal, no caso a anticlinal da serra das Porteiras ou Umburana.

As megadobras possuem linhas de charneira de direção NNE-SSW em duplo caimento. Estas dobras apresentam-se na forma de depressões sinformais, depressões antiformais, culminações sinformais ou culminações antiformais. São dobras abertas, geralmente assimétricas, quase cilíndricas, vergentes para oeste. São representadas pelas anticlinais da serra da Água Fria, da serra da Umburana (ou das Porteiras), do Furado Grande e do Canabrava, e pelas sinclinais da serra do Santo Antônio, das Palmeiras, do Boqueirão e de Covancas (Fig. 13).

Ao longo da serra da Onça ocorrem excelentes exposições que registram desde a base até o topo da sucessão sedimentar ocorrente nessa porção da bacia. Desde o seu limite leste com a serra da Água Fria até aproximadamente $17 \mathrm{~km}$ a oeste, sucedem megadobras abertas, ligeiramente assimétricas, conformadas em sinclinais e anticlinais cujos eixos mergulham suavemente para sudoeste (perfil CD; Fig. 14). A continuação para norte dessas estruturas foi constatada na seção sísmica (perfil AB; Fig. 10). Provavelmente estas sinformes e antiformes compõem estruturas maiores na forma de depressões antiformais e culminações sinformais, a exemplo da sinclinal de Covancas.

A sinclinal das Palmeiras e a anticlinal de Furado Grande revelam expressão conspícua na topografia, seus flancos são conformados por paredões da serra da Onça onde afloram os carbonatos basais da coluna sedimentar da área. Já a sinclinal do Angical e a anticlinal de Canabrava têm menor expressão na morfologia da área.

A foliação é representada pela clivagem plano axial $\left(\mathrm{S}_{1}\right)$ ao dobramento D1, apresentando-se na forma de leque ou convergente. A clivagem muitas vezes encontra-se pouco evidente. Localmente ela evolui para uma clivagem ardosiana embrionária que se desenvolve preferencialmente nos níveis mais pelíticos. As principais estruturas lineares observadas neste domínio foram a lineação de intersecção $\left(\mathrm{L}_{1 \times 0}\right)$ da clivagem $\mathrm{S}_{1}$ com o plano de acamamento $\left(\mathrm{S}_{0}\right)$ e estrias de natureza frágil observadas sobre algumas superfícies de acamamento, ou sobre planos de falhas e fraturas.

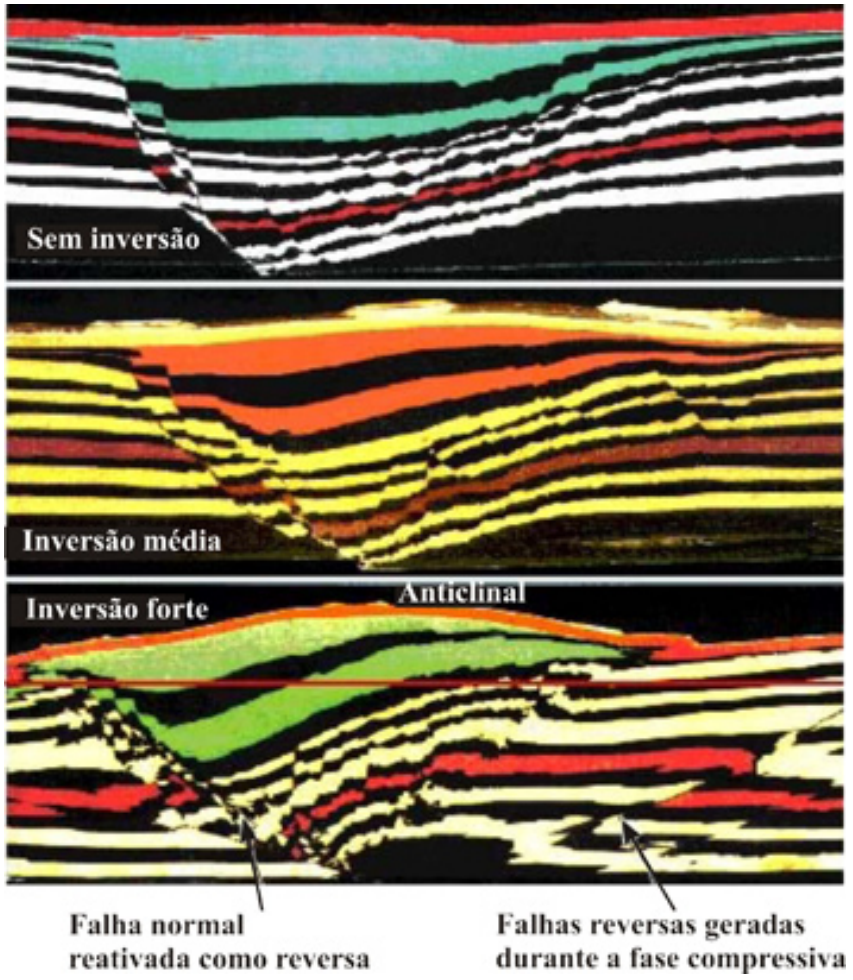

Figura 11 - Modelo físico de inversão de um hemigráben (Extraído de Schlische \& Whitjack 2007).

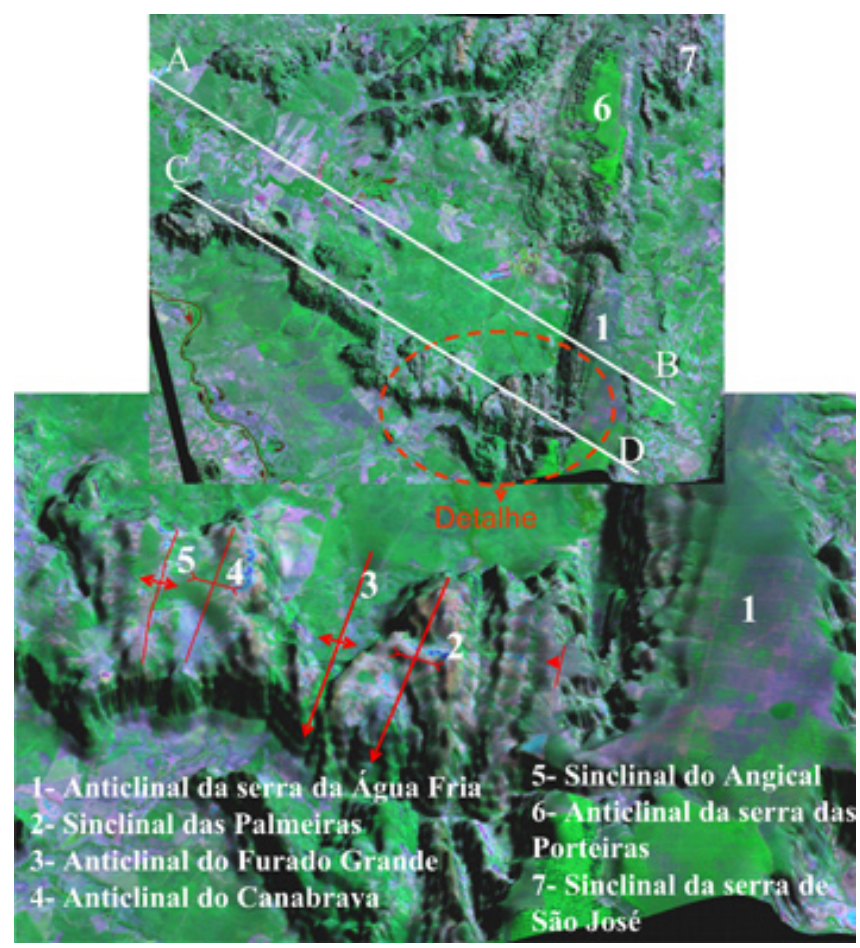

Figura 12 - Megadobras do domínio Oriental em perspectiva.

\section{DOMÍNIO CENTRAL}

Em subsuperficie Os horizontes da zona SP apresentam mergulho uniforme para oeste, em torno de $8^{\circ}$, 
Anticlinal da Serra da Água Fria

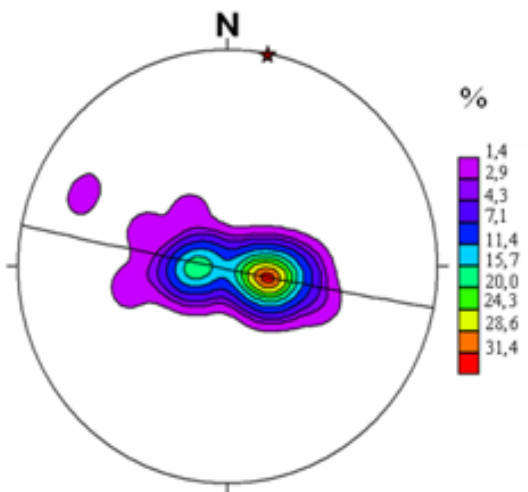

Dados:70; Máximos: 104/74 e 268/78,6
Anticlinal do Canabrava

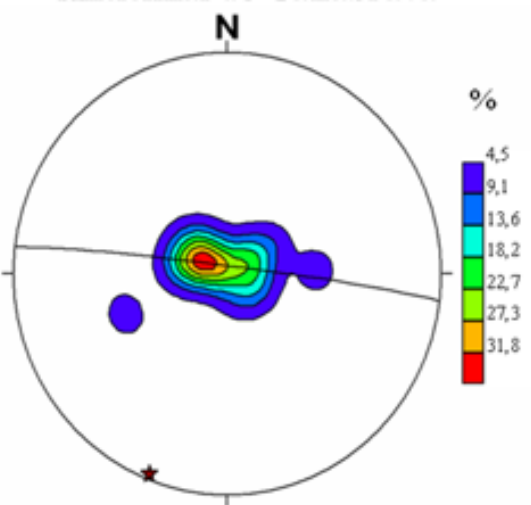

Dados:22; Máximo: 298/80

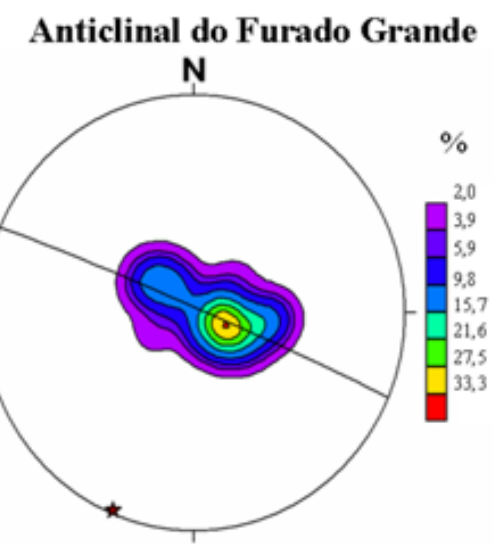

Dados:51; Máximos: 111/77 e 311/74
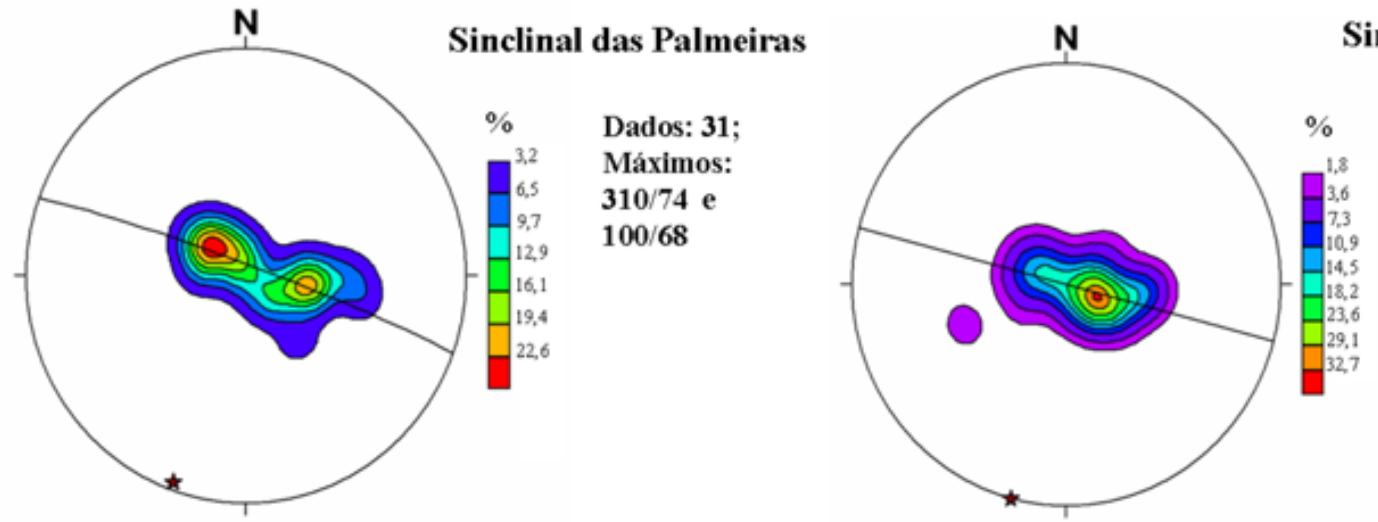

Sinclinal do Angical

Dados: 31;

Máximos:

$310 / 74$ e

$100 / 68$

Dados:55;

Máximo: 111/77

Figura 13 - Diagramas de contorno de pólos de acamamento de algumas megadobras do domínio Oriental.

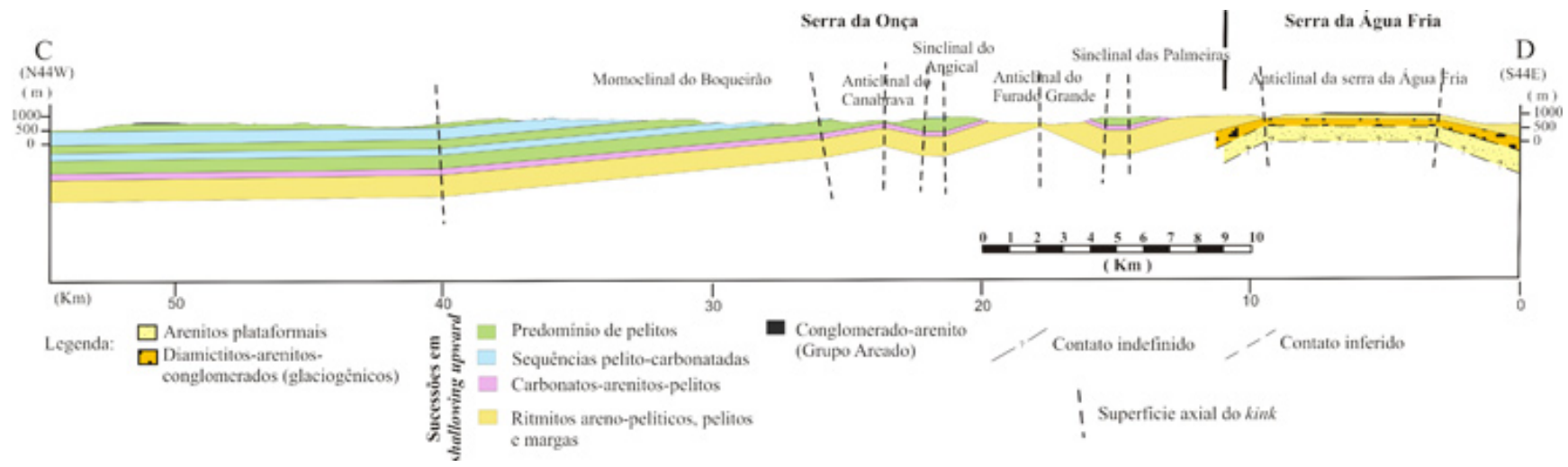

Figura 14 - Perfil geológico CD ao longo da serra da Onça (Modificado de Hercos 2008).

configurando parte de uma extensa monoclinal, denominada de monoclinal do Boqueirão. O topo Zona IF acompanha esse caimento com o mesmo ângulo de mergulho, já o topo do embasamento cristalino apresenta ângulos bem maiores. Em alguns locais a Zona IF é seccionada por falhas inversas com mergulhos para oeste. Em algumas partes do pacote sedimentar nota-se a presença de fault propagation folds, vergentes para leste e associadas a falhas inversas mergulhantes para oeste (Fig. 15).

Nivel superficial Esse domínio é limitado a leste pela anticlinal do Canabrava na serra da Onça e pelo Riacho Água Suja na serra das Porteiras ou Umburana e se estende por aproximadamente $13 \mathrm{~km}$ para oeste. No seu interior as camadas exibem mergulhos de 5 a 10 graus para WNW, configurando uma extensa monoclinal, que é provavelmente a continuação da monoclinal do Bo- 
queirão na direção sul (Fig. 16). As dobras de ordem inferior observadas em afloramentos são abertas a suaves, cilíndricas e, em geral, não mostram vergência.

\section{DOMÍNIO OCIDENTAL}

Em subsuperficie Situado no extremo oeste da área, esse domínio revela um pacote sedimentar suborizontal, levemente deformado e estruturado por inúmeras macrodobras suaves a abertas, ora com charneiras concêntricas ora angulares do tipo Kink (zona SP). Na zona IF interpretam-se falhas de baixo ângulo, com 30 a $40^{\circ}$ de mergulho para leste, limítrofes de blocos de embasamento, além de falhas subsidiárias, que foram reativadas como reversas durante a inversão. Uma dessas falhas limita o alto Oriental do Remanso a oeste. Ela apresenta um traço reto que em profundidade muda bruscamente de mergulho para $7^{\circ}$, definindo uma curvatura (bend) com concavidade para cima. A partir desta curvatura ocorrem superfícies de cisalhamento antitéticas cujos efeitos se propagam mormente até a base da cobertura sedimentar da zona SP (Figs. 7 e 10). Essa falha mergulha para leste e atravessa o Alto do Boqueirão a uma profundidade de $7000 \mathrm{~m}$. Ela provavelmente representa uma superfície de falhamento intra-crustal, possivelmente herdada da fase extensional, que foi reaproveitada durante a inversão.

Analisando a Zona SP através de uma perspectiva regional, observa-se que os horizontes conformam ondulações com grande comprimento de onda, em torno de $10 \mathrm{~km}$, e baixa amplitude, variando em torno de $100 \mathrm{~m}$, que são observadas apenas na seção sísmica.

Nivel superficial O Domínio Ocidental está limitado a leste pelas nascentes do rio Jatobá situadas na serra da Onça e se estende para oeste até os limites da área estudada. É caracterizado por se apresentar pouco deformado; as camadas assumem mergulhos inferiores ou iguais a 5 graus.

DISCUSSÃO DOS RESULTADOS Os dados de superfície e subsuperfície apresentados mostram que são dois os elementos estruturais preponderantes: as dobras e as falhas. As dobras predominam, sobretudo, na cobertura, e as falhas na porção mais profunda da seção. Através da sísmica se observa a relação causal entre estes dois elementos, ou seja, a geração das dobras de diferentes escalas induzida por fallhas (fault related fol$d s$ ), enraizadas em descolamentos ou a partir de reativação de falhas normais como reversas.

A interpretação de um hemigráben invertido na região da serra da Água Fria foi suportada pela geometria dos estratos de cobertura, em formato de arpão, e pela identificação, em profundidade, de uma depressão ligeiramente assimétrica limitada a oeste por uma falha de médio ângulo de rejeito reverso que afetou um bloco de embasamento cristalino, o Alto do Boqueirão. A presença de feições subsidiárias como as falhas de "atalho" (shortcut fault), comuns em hemigrábens invertidos, corroboram essa interpretação. Assim como a reprodução aproximada das geometrias dos dobramen-

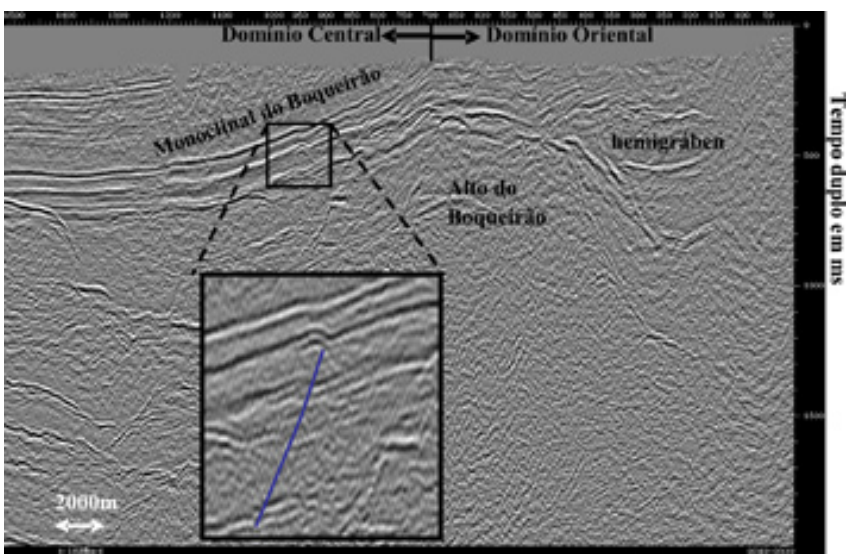

Figura 15 - Seção sísmica em tempo mostrando a monoclinal do Boqueirão e no detalhe, uma dobra de propagação de falha vergente para leste.

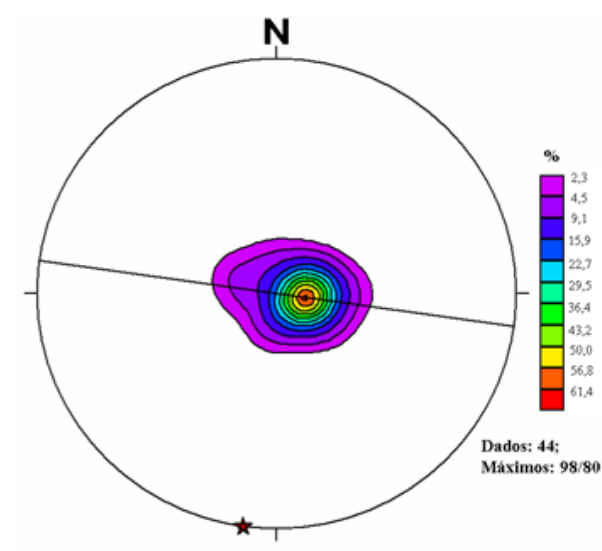

Figura 16 - Diagrama de contorno de pólos de acamamento do domínio central.

tos da cobertura em modelos físicos que simulam a inversão de hemigrábens.

O Alto do Boqueirão parece ter sido transladado para oeste ao longo da falha de baixo ângulo que o atravessa a $7000 \mathrm{~m}$ de profundidade, o que permitiu o seu soerguimento e conseqüente geração da monoclinal do Boqueirão. A presença de dobras desenvolvidas na cobertura deste alto, a existência dessa monoclinal sobre o seu flanco oeste e o desenvolvimento de dobras com vergência contrária à direção do transporte tectônico neste mesmo flanco corroboram essa hipótese.

Nielsen e Hansen (2000) definem zona de inversão como uma estrutura alongada que foi deformada em resposta a uma tectônica compressiva e experimentou posterior soerguimento. Segundo os autores, a estrutura interna de uma zona de inversão é variável e depende do arcabouço pré-inversão, do campo de tensões envolvido e do preenchimento da bacia. As estruturas 
de inversão mais comuns são falhas normais reativadas como falhas reversas, a formação de novas falhas reversas, as falhas de empurrão e as dobras.

De acordo com Cooper et al. (1993), uma bacia invertida é definida como uma depressão controlada por falhas e submetida a esforços compressionais-transpressionais que ocasionaram soerguimento e exposição parcial de seu preenchimento. Segundo esses autores, um dos principais critérios geométricos utilizados para reconhecer estruturas de inversão é a variação no relevo estrutural.

O relevo estrutural na região da serra da Água Fria se encontra muito acima, cerca de $2500 \mathrm{~m}$, do relevo regional medido a oeste da serra da Onça onde a deformação é incipiente. Provavelmente esta diferença aumenta para leste, na altura da serra do Cabral, onde litotipos atribuídos ao grupo Galho do Miguel afloram. Este significativo soerguimento está provavelmente relacionado ao alçamento de blocos do embasamento que atuaram na geração das megadobras e, por conseguinte, na exposição de rochas do Supergrupo Espinhaço. Litotipos atribuídos a essa unidade também afloram nas anticlinais das serras da Água Fria, das Porteiras e do Bicudo.

A geometria das estruturas de inversão é altamente dependente da geometria original da bacia ou das bacias, no caso de bacias sucessoras como a Bacia do São Francisco, controladas por sistemas de falhas. $\mathrm{Na}$ Bacia do São Francisco, os blocos do embasamento que foram envolvidos na deformação já conformavam horts.

A geometria de hemigrábens é controlada pela geometria das falhas mestras que os delimitam. Estas falhas mostram um deslocamento variável ao longo de seu traço sendo máximo na porção central e diminuindo ao longo da direção até se anular nas terminações laterais. Durante a inversão da bacia, a geometria dessas falhas mestras, reativadas como reversas, influiu consideravelmente na arquitetura geométrica das antiformes e sinformes moldadas na cobertura. Dessa forma, pode-se supor que as terminações das megadobras presentes na área de estudo e arredores estão associadas às variações geométricas e de deslocamento das falhas normais reativadas. Considerando essa premissa, propõe-se que o limite do compartimento tectônico thick skinned pode ser inferido, a norte e a sul, a partir dessas terminações.

O limite oeste pode ser tomado na altura do flanco oeste do Alto do Boqueirão (coincidente com o limite do domínio Oriental). O limite norte e sul podem ser considerados nas terminações das anticlinais das serras das Porteiras e do Cabral, respectivamente. O limite leste é balizado pela serra da Mineira. A área delimitada segundo esses critérios assemelha-se a uma protuberância dento da zona de antepaís, denominado neste trabalho de "Saliência de Pirapora" (Fig. 17). Esta saliência é coincidente, em parte, com o gráben do Espinhaço Meridional (L.B.Teixeira apud Souza Filho, 1995) ou gráben de Pirapora (Souza Filho 1995) ou Aulacógeno de Pirapora (Alkmim et al. 2006). Em tais circunstâncias a saliência define uma região onde houve a participação do embasamento na deformação da cobertura, favorecendo o alçamento do embasamento e a exumação de unidades mais antigas, relacionadas ao $\mathrm{Sg}$. Espinhaço. A interação entre reativação de falhas normais com movimentos horizontais explicaria a geometria estrutural na zona de transição da Saliência de Pirapora para o restante do antepaís sem embasamento envolvido.

O grau de soerguimento e a dimensão das dobras presentes na saliência de Pirapora indicam que a magnitude da inversão varia de leste para oeste. Tal variação sugere um zoneamento para os efeitos da inversão que afetou essa saliência, o que possibilita classificá-la em forte, média ou fraca. A zona de inversão forte estaria compreendida pela serra do Cabral e a região situada entre ela e a serra da Mineira. Entretanto, a magnitude da inversão segue aumentando para leste de modo contínuo, a partir do limite leste do corredor. A diferença entre as áreas das serras da Mineira e do Cabral é que na primeira ocorreu maior soerguimento e encurtamento relacionado com a inversão do embasamento o que provocou a emergência das falhas de empurrão e uma exumação relativamente mais intensa. Já a zona de inversão média seria limitada na altura da serra da Água Fria, a leste, e pela monoclinal do Boqueirão, a oeste. A partir daí até a altura do Bloco Oriental do Remanso tem-se a zona de inversão fraca que seria coincidente com o compartimento de antepaís sem embasamento envolvido de Alkmim et al. (1993).

Além do modelo de inversão de falhas normais, na literatura são apresentados e discutidos outros mecanismos para explicar a geração de dobras induzidas por falhas. Na área investigada, grande parte das mesodobras e dobras de menor ordem observadas em afloramentos, obedecem aos critérios geométricos de uma dobra por propagação de falha (fault-propagation fold). No entanto, as megadobras, mesmo sendo assimétricas, apresentam ângulos de mergulho do forelimb inferiores a 30 graus. É o caso da anticlinal da serra da Água Fria, cujo mergulho médio do forelimb (flanco oeste) é de 16 graus. $\mathrm{O}$ modelo teórico desse tipo de dobramento não admite ângulos menores do que $30^{\circ}$ para o flanco frontal da dobra (Shaw et al. 2005).

O dobramento por cisalhamento em zona triangular (trishear) é um modelo geométrico e cinemático que contempla dobras por propagação de falhas, com o envolvimento do embasamento cristalino (Esrlev 1991). O modelo trishear preconiza a formação de forelimbs externos com baixos mergulhos quando a razão de propagação por deslocamento é baixa. Na seção sísmica é possível observar uma feição que se assemelha a uma falha em profundidade cuja terminação estaria abaixo do alto do Boqueirão. Considerando esse modelo, a deformação envolve a rotação dos estratos no interior do gráben, promove o dobramento da cobertura sobrejacente e origina uma monoclinal (no caso a monoclinal do Boqueirão), sob uma baixa razão de propagação por deslocamento.

Naar e Suppe (1994) propõem um modelo cine- 


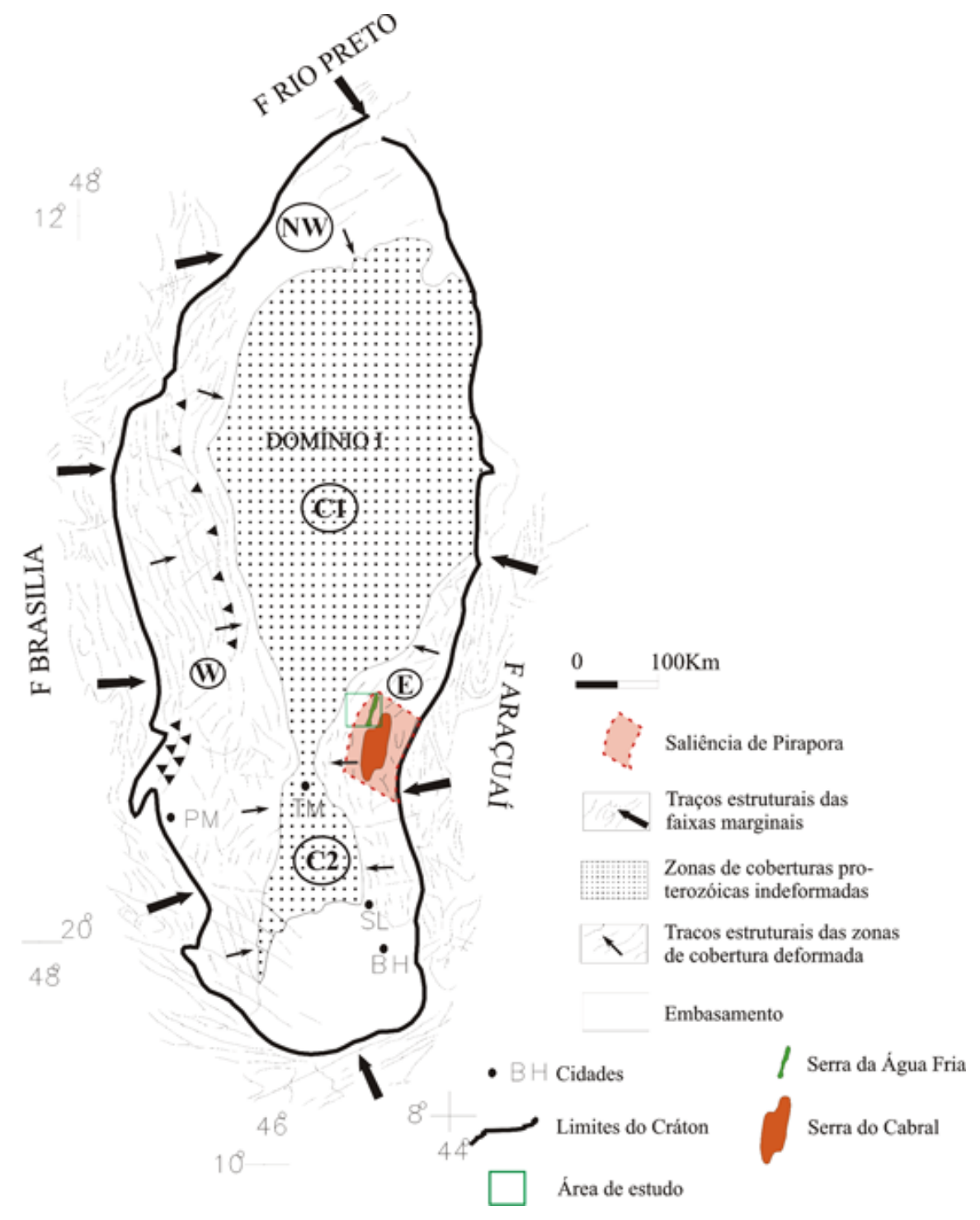

Figura 17 - Mapa regional do cráton São Francisco mostrando a Saliência de Pirapora.

mático de dobras por propagação de falhas que envolve o embasamento cristalino (Basement-involved), onde a evolução da dobra ocorre em resposta à migração de uma junção tríplice composta por 3 elementos: falhafalha-dobra. Esse modelo considera uma sucessão sedimentar formando uma cobertura (drape) sobre o embasamento cristalino. Já na área estudada a seqüência inferior se encontra estruturada em grábens e horts, onde o relevo do topo do embasamento cristalino é variável. Mesmo considerando a megasequência inferior como o embasamento relativo, verifica-se uma inconformidade na aplicação do referido modelo devido aos baixos ângulos de mergulho dos flancos frontais das megadobras (Ex: monoclinal do Boqueirão, anticlinal da serra da Água Fria). De acordo com o modelo teórico, o valor mínimo admitido para este ângulo é de 40 graus (Shaw et al. 2005).
CONCLUSÕES Os elementos estruturais observados em subsuperfície e superfície nos domínios Oriental, Central e Ocidental definidos no presente estudo, indicam que o segmento bacinal investigado registrou os efeitos de uma inversão, provavelmente relacionada ao evento compressional Brasiliano, que afetou o embasamento. Foram distinguidas várias feições que suportam tal proposição, a saber: grábens e horts limitados por falhas normais invertidas recobertos por estratos dobrados (maior encurtamento relativo), elevação considerável (cerca de $2900 \mathrm{~m}$ ) do relevo estrutural no domínio Oriental, soerguimento de blocos de embasamento (Ex.: Alto do Boqueirão cujo alçamento ocasionou a geração da monoclinal homônima), exumação de litotipos pertencentes ao Sg. Espinhaço (embasamento da bacia do São Francisco) no núcleo das megadobras (Ex.:anticlinais das serras da Água Fria e do Cabral), presença de falhas intra-crustais de baixo ângulo que 
mergulham para leste e passam por baixo de blocos de embasamento soerguidos (caso do Alto do Boqueirão).

A partir da integração dos dados analisados, propõe-se que o segmento estudado pertence a um compartimento tectônico que constituí uma protuberância dentro da zona de antepaís, aqui denominada de "Saliência de Pirapora", onde o embasamento foi envolvido na deformação das rochas da cobertura, configurando uma tectônica thick-skinned, em oposição ao modelo de deformação epidérmica (thin-skinned) vigente.

A magnitude da inversão e, consequentemente, a quantidade de encurtamento varia de leste para oeste, de forma que o compartimento Oriental exibe maior grau de inversão relativo e maior encurtamento, enquanto no Ocidental se observa uma inversão fraca, cujos efeitos afetaram somente o nível estrutural mais profundo. A magnitude da inversão segue aumentando para leste, além dos limites da área estudada.

A presença de dados de subsuperfície em apenas uma direção dificulta o entendimento da geometria da bacia em três dimensões. Não há como saber, por exemplo, a real geometria dos grábens e horsts, ou o verdadeiro mergulho das falhas observadas na seção, ou a variação dos estilos estruturais e deposicionais na direção longitudinal e muitas outras questões importantes para a reconstrução do arcabouço tectono-estratigráfico. Apesar dessas limitações, os dados sísmicos, juntamente com dados de campo e de poços, clarearam as relações tectono-estratigráficas existentes em subsuperfície, ampliando o entendimento da evolução estrutural na zona de antepaís do cráton São Francisco.

Agradecimentos Os autores agradecem à FAPEMIG pelo apoio financeiro para o projeto de pesquisa (processo CEX 895/95), à Petrobras e a ANP pela cessão dos dados sísmicos e de poços, e aos revisores anônimos da RBG. Marcelo A. Martins Neto agradece ao CNPq pela concessão de Bolsa de Produtividade em Pesquisa vinculada ao projeto.

\section{Referências}

Alkmim F.F., Brito Neves B.B., Alves J.A.C. 1993. Arcabouço tectônico do Cráton do São Francisco - uma revisão. In: Dominguez J.M. \& MISI A. (eds). O Cráton do São Francisco. Reunião preparatória do II Simpósio sobre o Cráton do São Francisco, Salvador, SBG/Núcleo BASE/SGM/CNPq. p. 45-62.

Alkmim F.F. \& Martins-Neto M.A. 2001. A Bacia Intracratônica do São Francisco: arcabouço estrutural e cenários evolutivos. In: Pinto C.P., Martins-Neto M.A. (eds.) Bacia do São Francisco: geologia e recursos naturais. Belo Horizonte: SBG-MG, p. 9-30.

Alkmim F.F., Marshak S., Pedrosa-Soares A.C., Peres G.G., Cruz S.C.P., Whittington W. 2006. Kinematic evolution of the Araçuaí-West Comgo orogen in Brazil and África: Nutcracker tectonics during the Neoproterozoic assembly of Gondwana. Precambrian Research, 149:43-64.

Almeida F.F.M. 1977. O Cráton do São Francisco. Revista Brasileira de Geociências, 7(4):349-364.

Bacellar L.A.P. 1989. Geologia Estrutural do Supergrupo São Francisco ao longo da seção regional CoromandelTrês Marias-Conselheiro Mata, MG. Dissertação de mestrado, Departamento de Geologia (Escola de Minas), Universidade Federal de Ouro Preto, Ouro Preto, 128p.

Bosum W. 1973. O levantamento aeromagnético de Minas Gerais e Espirito Santo e sua sequência quanto à estrutura geológica. Revista Brasileira de Geociências, 3:149159.

Branco J.J.R. \& Costa M.T. 1961. Roteiro da excursão Belo Horizonte - Brasília. In: SBG, Congresso Brasileiro de Geologia, 14, Belo Horizonte, Roteiro de excusões, 25p. (Publicação 15).

Brandalise L.A. 1980. Projeto Sondagem do Bambui em Minas Gerais. Belo Horizonte, CPRM/DNPM, relatório final, vol.1.

Braun O.P.G., Martins M., Oliveira W.J. 1993. Continuidade das seqüências rifeanas sob a Bacia do São Francisco constatada por levantamentos geofísicos em Minas Gerais. In: SBG, Simp. do Cráton do São Francisco, 2, Salvador, Anais, p.164-166.

Carvalho R.T. \& Epstein A.H.L. 1967. A Geologia da Folha Pirapora, Rio de Janeiro, Geoexplorações, 52p.

Cooper M.A. \& Williams G.D. (eds.) 1989. Inversion tectonics. Oxford, Alden Press, 375p.

Costa K.V., Penha U.C., Gonzaga G.M. 1998. Dados preliminares sobre os sedimentos cretáceos na região de Jequitaí/MG. In: Congresso Brasileiro de Geologia, 40, Belo Horizonte, Anais, p. 274.

Dupont H. 1995. O Grupo Conselheiro Mata no seu quadro paleogeográfico e estratigráfico. In: Simpósio de Geologia de Minas Gerais, 8, Diamantina, Atas, p. 9-10.

Dupont H. 1996. O Supergrupo São Francisco entre a Serra do Cabral e as Serras do Espinhaço e de Minas. Estudo Estratigráfico e Estrutural e Relações de Contato com o Supergrupo Espinhaço. SBG, Cong. Bras. de Geol., 39, SBG, Salvador, Anais, 5:489-493.

Erslev E.A. 1991. Trishear fault-propagation fold. Geology, 19(6):617-620.

Espinoza J.A.A. 1996. Sistemas deposicionais e relações estratigráficas da Tectonossequência Conselheiro Mata, na borda leste da Serra do Cabral, Minas Gerais, Brasil. Dissertação de Mestrado, Departamento de Geologia, Universidade Federal de Ouro Preto, 130p.

Fugita A.M. \& Clark J.G. 2001. Recursos energéticos da Bacia do São Francisco: hidrocarbonetos líquidos e gasosos. In: Pinto C.P., Martins-Neto M.A. (eds.) Bacia do São Francisco: Geologia e Recursos Naturais. Belo Horizonte (SBG/MG), p. 265-284.

Gomes J.C.F. 1949. Contribuição ao conhecimento da geologia de Jequitaí (Minas Gerais). Revista da Escola de Minas, 14:17-43.

Gravenor C.P. \& Monteiro R.L.B.P. 1983. Ice-thrust features and a possible intertillite pavement in the Proterozoic 
Macaúbas Group, Jequitaí area, Minas Gerais, Brazil. Journal of Geology, 91:113-116.

Haraly N.L.E. \& Hasui Y. 1985. Interpretation of gravity and magnetic data, Central and Eastern Brazil. In: Hinze W.J. (ed.) The utility of regional gravity and magnetic anomaly maps. Society of Exploration Geophysicists, Tulsa, Oklahoma, p. 124-131.

Hercos C.M. \& Martins-Neto M.A. 1997. Considerações sobre os supergrupos São Francisco e Espinhaço ao longo da borda oeste da serra da Água Fria (MG). In: SBG/ MG, Simpósio de Geologia de Minas Gerais, 9, Ouro Preto, Anais, p.19-21.

Hercos C.M. (no prelo). Arcabouço tectono-estratigráfico da Bacia do São Francisco nos arredores das serras da Água Fria e da Onça, porção centro-norte do estado de Minas Gerais. Dissertação de Mestrado, Departamento de Geologia, Escola de Minas, Universidade Federal de Ouro Preto, Ouro Preto.

Inda H.A.V., Schorscher H.D., Dardenne M.A., Schobbenhaus C., Haralyi N.L.E., Azevedo Branco P.C., Ramalho R. 1984. O Cráton do São Francisco e a faixa de dobramento Araçuaí. In: Schobbenhaus C., Almeida Campos C., Derze G.R., Asmus H.E. (eds.) Geologia do Brasil. Brasília, DNPM, p. 194-284.

Isotta C.A.L., Rocha-Campos A.C., Yoshida R. 1969. Striated pavement of the upper Precambrian glaciation in Brazil. Nature, 222(5192):466-468.

Lesquer A., Almeida F.F.M., Davino A., Lachaud J.C., Mailard P. 1981. Signification structurale dês anomalies gravimetriques de la partie sud du Craton du São Francisco (Brésil). Techtonophysics, 76:273-293.

Marinho F. 1993. Interpretação dos dados gravimétricos e aeromagnetométricos da porção central da Bacia Proterozóica do São Francisco - noroeste do Estado de Minas Gerais. In: SBG, Simpósio do Cráton São Francisco, 2, Salvador, Salvador, Anais, p.170-172.

Martins-Neto M.A. \& Hercos C. M. 2002. Sedimentation and tectonic setting of Early Neoproterozoic glacial deposits in southeastern Brazil. In: Alterman W. \& Corcoran P.L. (ed.) Precambrian Sedimentary Environments: a modern approach to ancient depositional systems. Special Publication of the International Association of Sedimentologists, IAS-Blacwell, 33:383-403.

Martins-Neto M.A. 2005. A bacia do São Francisco: arcabouço estratigráfico e estrutural com base na interpretação de dados de superfície e subsuperfície. In: Simpósio do Cráton do São Francisco, 3, Salvador, Anais, p. 283286.

Moraes L.J. \& Guimarães D. 1930. Geologia da região diamantífera do norte de Minas Geraes. Annaes da Academia Brasileira de Sciencias, tomo II(3):153-186.

Narr W. \& Suppe J. 1994. Kinematics of Basement-Involved Compressive Structures. American Journal of Science, 224(7):802-860.

Nielsen S.B. \& Hansen D.L. 2000. Physical explanation of the formation and evolution of inversion zones and marginal troughs. Geology, 8(10):875-878.

Oliveira J.R.P. 1989. Comportamento estrutural dos grupos
Macaúbas e Bambuí na porção centro-norte de Minas Gerais. Dissertação de Mestrado, Departamento de Geologia da Universidade Federal de Ouro Preto, Ouro Preto, 112p.

Paiva Filho A. \& Ponçano W.L. 1972. Mapa geológico preliminar da Região de Jequitaí, Estado de Minas Gerais. In: SBG, Congresso Brasileiro de Geologia, 26, Belém, Anais, 1:95-102.

Romeiro-Silva P.C. \& Zálan P.V. 2005. Contribuição da sísmica de reflexão na determinação do limite oeste do cráton do São Francisco. In: Simpósio do Cráton do São Francisco, 3, Salvador, Atas, p. 44-48.

Schlische R.W. \& Withjack M.O. 2007. Rift basin architecture and evolution. 13p. Disponível em: http: www.Ideo. columbia.edu/ polsen/nbcp/breakupintro.html. Acessado em outubro de 2007.

Sgarbi G.N.C., Sgarbi P.B. de A., Campos J.E.G., Dardenne M.A., Penha U.C. 2001. Bacia Sanfranciscana: o registro fanerozóico da bacia do São Francisco. In: Pinto C.P. \& Martins-Neto M.A. (Eds) Bacia do São Francisco: Geologia e Recursos Naturais. Belo Horizonte, SBG/ MG, p. 93-138.

Shaw J. H. Connors C., Suppe J. (eds.) 2005. Seismic interpretation of contractional fault-related folds. Am. Assoc. of Pet. Geol. Seismic Atlas, studies in geology 53, Tulsa, 156p.

Souza Fo R.G. 1995. O arcabouço estrutural da porção externa da Faixa Araçuaí na Serra do Cabral (MG) e o constraste de estilos deformacionais entre os supergrupos Espinhaço e São Francisco. Dissertação de mestrado, Departamento de Geologia, Escola de Minas, Universidade Federal de Ouro Preto, 148p.

Teixeira L.B., Martins M., Braun O.P.G. 1993. Evolução geológica da Bacia do São Francisco com base em sísmica de reflexão e métodos potenciais. In: SBG, Simp. Craton São Francisco, 2, Salvador, Atas, 179-181.

Uhlein A. 1991. Transição cráton-faixa dobrada: Exemplo do Cráton do São Francisco e da Faixa Araçuaí (Ciclo Brasiliano) no Estado de Minas Gerais. Tese de Doutoramento, Universidade de São Paulo, São Paulo, 295p.

Ussami N. 1981. Interpretação dos dados aeromagnéticos na área compreendida entre $42^{\circ}-47^{\circ} \mathrm{W}$ e $15^{\circ}-19^{\circ} \mathrm{S}$ (Minas Gerais, Brasil). Dissertação de Mestrado, Instituto de Geociências da Universidade de São Paulo, São Paulo, 119p.

Viveiros J.F.M. \& Walde D.H.D. 1976. Geologia da Serra do Cabral, Minas Gerais, Brasil. Münster. Forsch. Geol. Paläont., 38/39:15-25.

Walde D.H.G. 1978. Desenvolvimento faciológico do précambriano entre a Serra Mineira e a Serra do Cabral (região sudoeste da Serra do Espinhaço, Minas Gerais). In: SBG, Congresso Brasileiro de Geologia, 30, Recife, Anais, 2:711-725.

Manuscrito BR 27

Submetido em 20 de dezembro de 2007 Aceito em 30 de maio de 2008 